\title{
The BRIDGE HadCM3 family of climate models: HadCM3@Bristol v1.0
}

Paul J. Valdes ${ }^{1}$, Edward Armstrong ${ }^{1}$, Marcus P. S. Badger ${ }^{1,2}$, Catherine D. Bradshaw ${ }^{3}$, Fran Bragg ${ }^{1}$, Michel Crucifix ${ }^{4}$, Taraka Davies-Barnard ${ }^{1,5}$, Jonathan J. Day ${ }^{6}$, Alex Farnsworth ${ }^{1}$, Chris Gordon ${ }^{7}$, Peter O. Hopcroft ${ }^{1}$, Alan T. Kennedy ${ }^{1}$, Natalie S. Lord ${ }^{1}$, Dan J. Lunt ${ }^{1}$, Alice Marzocchi ${ }^{8}$, Louise M. Parry ${ }^{1,9}$, Vicky Pope ${ }^{11}$, William H. G. Roberts ${ }^{1}$, Emma J. Stone ${ }^{1}$, Gregory J. L. Tourte ${ }^{1}$, and Jonny H. T. Williams ${ }^{10}$

${ }^{1}$ School of Geographical Sciences, University of Bristol, Bristol, UK

${ }^{2}$ School of Environment, Earth and Ecosystem Sciences, The Open University, Milton Keynes, UK

${ }^{3}$ Applied Science group, Met Office Hadley Centre, Exeter, UK

${ }^{4}$ Earth and Life Institute, Georges Lemaître Centre for Earth and Climate Research, Université catholique de Louvain, Louvain-la-Neuve, Belgium

${ }^{5}$ College of Engineering, Mathematics, and Physical Sciences, University of Exeter, Laver Building, North Park Road Exeter, EX4 4QE, UK

${ }^{6}$ Department of Meteorology, University of Reading, Reading, UK

${ }^{7}$ Centre for Climate Research Singapore, Meteorological Service Singapore, Singapore

${ }^{8}$ Department of the Geophysical Sciences, The University of Chicago, Chicago, IL, USA

${ }^{9}$ Scottish Environment Protection Agency (SEPA), Perth, UK

${ }^{10}$ National Institute of Water and Atmospheric Research (NIWA), Wellington, New Zealand

${ }^{11}$ Met Office, Hadley Centre, Fitzroy Road, Exeter, UK

Correspondence to: Paul J. Valdes (p.j.valdes@ bristol.ac.uk)

Received: 20 January 2017 - Discussion started: 8 February 2017

Revised: 28 June 2017 - Accepted: 7 July 2017 - Published: 12 October 2017

\begin{abstract}
Understanding natural and anthropogenic climate change processes involves using computational models that represent the main components of the Earth system: the atmosphere, ocean, sea ice, and land surface. These models have become increasingly computationally expensive as resolution is increased and more complex process representations are included. However, to gain robust insight into how climate may respond to a given forcing, and to meaningfully quantify the associated uncertainty, it is often required to use either or both ensemble approaches and very long integrations. For this reason, more computationally efficient models can be very valuable tools. Here we provide a comprehensive overview of the suite of climate models based around the HadCM3 coupled general circulation model. This model was developed at the UK Met Office and has been heavily used during the last 15 years for a range of future (and past) climate change studies, but has now been largely superseded for many scientific studies by more recently developed mod-
\end{abstract}

els. However, it continues to be extensively used by various institutions, including the BRIDGE (Bristol Research Initiative for the Dynamic Global Environment) research group at the University of Bristol, who have made modest adaptations to the base HadCM3 model over time. These adaptations mean that the original documentation is not entirely representative, and several other relatively undocumented configurations are in use. We therefore describe the key features of a number of configurations of the HadCM3 climate model family, which together make up HadCM3@Bristol version 1.0. In order to differentiate variants that have undergone development at BRIDGE, we have introduced the letter $\mathrm{B}$ into the model nomenclature. We include descriptions of the atmosphere-only model (HadAM3B), the coupled model with a low-resolution ocean (HadCM3BL), the high-resolution atmosphere-only model (HadAM3BH), and the regional model (HadRM3B). These also include three versions of the land surface scheme. By comparing with 
observational datasets, we show that these models produce a good representation of many aspects of the climate system, including the land and sea surface temperatures, precipitation, ocean circulation, and vegetation. This evaluation, combined with the relatively fast computational speed (up to 1000 times faster than some CMIP6 models), motivates continued development and scientific use of the HadCM3B family of coupled climate models, predominantly for quantifying uncertainty and for long multi-millennial-scale simulations.

\section{Introduction}

This paper describes the variants of the HadCM3 family of climate models (all of which can be classed as general circulation models, GCMs), produced by the UK Hadley Centre/Met Office, and which remain in regular use by a number of research groups, including the Bristol Research Initiative for the Dynamic Global Environment group (BRIDGE, http://www.bristol.ac.uk/geography/ research/bridge). HadCM3 originated in the late 1990s with developments to the atmosphere model, HadAM3 (Pope et al., 2000). Together with improvements to the ocean GCM, this enabled the development of HadCM3 (Gordon et al., 2000), which was one of the first coupled atmosphere-ocean GCMs that did not require flux correction to maintain a reasonable present-day climate, i.e. the artificial adjustments of water, heat, and momentum in order to maintain a stable climate. It has been extensively used for scientific studies of future climate change (e.g. Stott et al., 2000; Johns et al., 2003; Smith et al., 2007; Stott and Kettleborough, 2002) and is heavily cited, including in the 2007 IPCC report (IPCC, 2007), and was still included in the 2013 report. The family of models has the advantage of now being very well known in terms of their strengths and weaknesses, as numerous studies have shown and classified model biases and forecast skill at representing the mean climate state as well as variability (e.g. Toniazzo et al., 2007; Spencer et al., 2007). The model family has now been superseded by the HadGEM2 (HadGEM2 Development Team, 2011) and HadGEM3 (Williams et al., 2015) families of models.

Compared to more recent models, HadCM3 is relatively low resolution but continues to perform reasonably well, at least with respect to its mean climate (Flato et al., 2013; Reichler and Kim, 2008). It also has the great benefit of computational speed, being more than 1000 times faster than some of the most recent and complex versions of the UK Met Office Unified Model (UM). This computational speed is particularly valuable for long-term simulations (necessary for many palaeoclimate simulations, studies which investigate the carbon cycle and the evolution of ice sheets) and for large ensembles (necessary for investigating the model's sensitivity to multiple parameters and quantifying the uncertainty in the model's response to forcing). Long model runs are also crucial for understanding unforced variability in the climate system (e.g. Collins et al., 2001).

Palaeoclimate simulations typically need many hundreds of model years to reach near equilibrium in the surface and intermediate ocean and many thousands of years to reach equilibrium in the deep ocean. Moreover, there recently has been an increasing need to be able to consider the transient behaviour of past climate change. This has previously been tackled using the HadCM3 family of models by using either multiple "snapshot" simulations (e.g. Hewitt et al., 2001; Singarayer and Valdes, 2010; Lunt et al., 2016; Marzocchi et al., 2015b) or by performing fully transient simulations for multi-centennial or -millennial timescales (e.g. Tett et al., 2006; Hopcroft et al., 2014).

Faster models are also invaluable for investigating the sensitivity and robustness of results to changes in the initial conditions of the model and changes in boundary conditions such as topography, as numerous simulations can be performed (Roberts and Valdes, 2017). Additionally, they are ideal for investigating anthropogenic changes on long timescales (Gregory et al., 2004; Ridley et al., 2005) and for performing perturbed parameter ensembles to rigorously calculate the probability density functions of either the mean or extreme climates (e.g. using HadCM3 variants, Murphy et al., 2007; Booth et al., 2012; Jackson and Vellinga, 2013; Schaller et al., 2016; Davies-Barnard et al., 2014; Armstrong et al., 2016; Stainforth et al., 2005). Computational speed also aids more speculative studies. For instance, many early geoengineering simulations were run using variants of the HadCM3 family of models (such as Ridgwell et al., 2009; Singarayer et al., 2009; Lunt et al., 2008; Irvine et al., 2010).

In response to the need for fast models, Earth system models of intermediate complexity (EMICs) (Claussen et al., 2002) have been developed. These models frequently achieve their speed by heavily parameterising the atmospheric response, even though atmospheric processes transport twothirds of the total heat from Equator to pole and play a vital role in the hydrological cycle. It is, therefore, also important to have a class of fast models that is equivalent to full atmosphere-ocean general circulation models (GCMs). Some EMICS do represent the dynamics of the atmosphere; for instance, LOVECLIM (Goosse et al., 2010) uses a three-level quasi-geostrophic atmosphere. Similarly, FAMOUS (part of the HadCM3 family) includes a full primitive equation atmosphere but at low resolution (Jones et al., 2005; Smith et al., 2008; Smith, 2012). Hence the division between EMICs and full complexity models is becoming increasingly blurred and we consider that the HadCM3 family provides a further bridge in the spectrum of models between intermediate complexity models and full complexity, stateof-the art models.

Since its introduction, HadCM3 (and related models) has undergone a number of changes, bug fixes, and adaptations. The original model described in Pope et al. (2000) and Gordon et al. (2000), i.e. HadCM3 with MOSES1, is still used, 
but now many other versions exist. Some groups have largely stuck to the standard release of the model (e.g. Stainforth et al., 2005). Other groups have incorporated a variety of bug fixes and scientific changes; in particular, many papers have used a revised land surface scheme, MOSES2.1 (e.g. Dolan et al., 2015), but this is relatively poorly documented.

Therefore, in this paper, we aim to rectify this for the wide range of HadCM3 variants currently in use within the BRIDGE modelling group. Our implementations of the models have diverged from other versions, and so here we aim to provide clear documentation of our version of each model. In order to do this more clearly, we use the nomenclature HadCM3B, in order to differentiate model variants that have undergone development at Bristol from those originally developed at the Met Office. We have followed a specific modelling philosophy in which we attempt to minimise the differences between model configurations, particularly when changing resolution. For instance, previously published descriptions of HadRM3 (Jones et al., 1995) and HadAM3H (Hudson and Jones, 2002; Arnell et al., 2003) use slightly improved physics to HadCM3, but we choose to keep the same physics (except for specific changes related to resolution).

We include detailed descriptions of each module of the models, differences between variants, and comparison with observations across a range of metrics. This will increase transparency, traceability, and scientific openness. By detailing the changes and variations of these models, and providing an extensive comparison to observational data, we hope to show that these models remain useful tools for climate simulation and are suitable for further scientific use. Furthermore, we shall show that despite their relative simplicity, the models simulate the modern climate with comparable accuracy to many of the latest CMIP5 models.

To this end, we first describe the "base" model, which we term HadCM3B-M1. This is essentially almost identical to that of Gordon et al. (2000), but with some minor modifications made by BRIDGE detailed in Sect. 2.1, to which all the other models will be compared (Sect. 2). As such, because it is largely simply bug fixes, it could be argued that HadCM3B-M1 is not a different model to the original, but we include it for completeness. We then subsequently discuss different land surface schemes (Sect. 3), followed by model variants with different ocean or atmospheric resolutions (Sect. 4). Finally, we evaluate the models' performance when compared to observations and CMIP5 models, to show that they recreate many key aspects of the climate system, and show which models are more suitable for certain applications (Sect. 5).

\section{Overview of HadCM3@Bristol}

The family of models has at its core HadCM3. From this core, variants are derived according to resolution, land surface scheme, and components. In order to distinguish variants that have undergone further development at Bristol to those originally developed at the Met Office, we include the letter $B$ for Bristol in the model acronym. As discussed in the text, the changes between the Bristol and Met Office variants are small in some cases; however, we believe they warrant documentation to remove ambiguity. The model family is then split into groups: HadCM3B, HadCM3BL (HadCM3B but lower ocean resolution), HadAM3B (HadCM3B but atmosphere-only), HadAM3BH (HadAM3B but higher resolution), HadRM3B (HadAM3B but regional), and FAMOUS (HadCM3L but lower atmosphere resolution).

FAMOUS is a low-resolution model derived from HadCM3, sharing much of the same physics, but with some numerical modifications suitable for the low resolution and which give quicker run times. It is well documented elsewhere (Jones, 2003; Smith et al., 2008) and will not be described again in detail here, although some comparisons with FAMOUS are included for completeness.

Run times for M1 model versions are compared in Table 3 for typical configurations. This demonstrates the efficiency of FAMOUS-M1 at around several modelled centuries per day on just eight cores, and the relatively high computational cost of the two high-resolution model versions (HadAM3BH and HadRM3B). This compares with 1.87 model years per day on 1152 cores for the higher-resolution version of HadGEM3-GC2 (Williams et al., 2015). As it is normal for these types of numerical models, it is to be noted that the relationship between the number of cores used and the model efficiency is not linear, i.e. using twice as many cores does not make the model twice as fast, and eventually adding more cores has no positive effect on the model efficiency.

The nomenclature adopted for the HadCM3@Bristol model variants is $\operatorname{Had}\langle\mathrm{Com}\rangle \mathrm{M} 3 \mathrm{~B}\langle\operatorname{Res}\rangle-\langle\mathrm{Land}\rangle\langle\mathrm{Veg}\rangle$, where

$\langle\mathbf{C o m}\rangle$ (components) is one of

A - atmosphere-only model;

C - coupled model;

$\mathbf{R}$ - regional model.

$\langle\mathbf{R e s}\rangle$ (resolution) is one of

$\mathbf{L}$ - lower than standard-resolution ocean;

$\mathbf{H}$ - higher than standard-resolution atmosphere;

blank - standard resolution.

$\langle$ Land $\rangle$ (land surface scheme) is one of

M1 - MOSES1 land surface exchange scheme;

M2.1a - MOSES2.1a land surface exchange scheme;

M2.2 - MOSES2.2 land surface exchange scheme.

$\langle\mathbf{V e g}\rangle$ (vegetation) is one of 
blank or $N$ - no change to vegetation (i.e. static vegetation distribution);

E - vegetation predicted using TRIFFID, but in "equilibrium" mode;

D - same as E above, but fully dynamic model.

As such, the original "base" model described in Gordon et al. (2000) which has undergone some minor modifications (see Sect. 2) is named HadCM3B-M1.

\section{HadCM3B-M1}

This section describes the "core" model, HadCM3B-M1, to which all other variants will be compared in this paper. This variant of the family was originally the most commonly used, and is still used for studies where the vegetation is known, and as such can be prescribed where relatively short simulations are sufficient for the science questions being addressed and where the ocean plays a critical role and as such high resolution is desirable (e.g. Bragg et al., 2012).

This model is a three-dimensional, fully dynamic, coupled atmosphere-ocean global climate model without flux adjustment. Our version of the model is very similar to that described by Gordon et al. (2000). Our aim is to provide a full description of how our version differs from that in Gordon et al. (2000) followed by a brief description of the core model. A full description of the Gordon et al. (2000) version can be found in the UK Met Office technical notes http: //cms.ncas.ac.uk/wiki/Docs/MetOfficeDocs; the base model code is currently available to view at http://cms.ncas.ac.uk/ code_browsers/UM4.5/UMbrowser/index.html, but it should be noted that additional modifications are required for the full scientific definition of the model as described here (see Sect. "Code availability").

\subsection{Modifications for the Bristol versions of HadCM3B-M1 and HadAM3B}

We have benchmarked the standard version of HadCM3-M1 supplied by the UM Met Office against existing model results from the published Hadley Centre version of Gordon et al. (2000) and confirmed that we could reproduce the results within the normal statistical variability of the model. Subsequently a few relatively minor changes have been made. These include the following.

\subsubsection{HadCM3B-M1}

- Correction of a small bug in the Visbeck horizontal eddy mixing scheme (Visbeck et al., 1997) which was originally included in the standard configuration of the model to ensure compatibility with previous versions.

- Use of versions of the radiation and primary field advection schemes that are scientifically identical to the standard version and which make the model faster but which are not bit reproducible.

\subsubsection{HadAM3B}

- Fixes to a few array bounds errors (which may or may not have an impact on the scientific results).

- Multiple other bug fixes which did not change the science but corrected problems with some aspects of the code and diagnostic outputs.

- There were two small bugs in the conservation of atmospheric mass, and the computation of vertical velocity, fixes to which are not included in the standard release version of HadAM3 but are included in HadCM3B. We include these bug fixes in all versions of the code so that our atmosphere model (HadAM3B) is $100 \%$ identical to the atmosphere component of our version of HadCM3B.

- There is also another important code fix (SteenmanClark, personal communication) which is vital to include. If this is not included, then some compilers will lead to a large (e.g. $0.75^{\circ} \mathrm{C}$ bias in global mean surface air temperature) error in mean climate.

These modifications are included in the supplementary information. The overall impact of these changes on the climate simulation is very small.

\subsection{Atmosphere (HadAM3B)}

The atmosphere component of HadCM3B is almost identical to the atmosphere component of HadAM3B, which is the atmosphere-only variant with fixed sea surface temperatures (SSTs). The modifications made at Bristol are highlighted in Sect. 2.1, beyond which the model is the same as that described by Pope et al. (2000). HadAM3B has a Cartesian grid with a horizontal resolution of $96 \times 73$ grid points $\left(3.75^{\circ}\right.$ longitude $\times 2.5^{\circ}$ latitude) with 19 hybrid levels (sigma levels near the surface, changing smoothly to pressure levels near the top of the atmosphere) in the vertical (Simmons and Strüfing, 1983) and uses a 30 min time step. HadAM3B solves the primitive equation set of White and Bromley (1995) which includes certain terms necessary to conserve both energy and angular momentum. Equations are solved through the use of a grid-point scheme, specifically the Arakawa staggered B-grid (Arakawa and Lamb, 1977), on a regular latitude-longitude grid in the horizontal. At high latitudes, Fourier filtering of higher wave-number dynamics is used to remove sub-grid-scale variability. A split-explicit time scheme conserves mass, mass-weighted potential temperature, moisture, and angular momentum, and ensures the reliability for solving equations on long timescales, which is particularly important for climate modelling (Van der Wal, 1998). 
As with any climate model, a number of parameterisation schemes are needed within HadAM3B to represent certain physical processes which occur on sub-grid scales.

- Precipitation is dealt with in two schemes: (i) the large-scale precipitation scheme, and (ii) the convection scheme. The large-scale precipitation scheme removes cloud water resolved on the grid scale, i.e. frontal precipitation. This is done via a simple bulk parameterisation scheme converting water content into precipitation (Wilson, 1998). The convection scheme (Gregory et al., 1997) uses a mass-flux scheme with the addition of convective downdrafts.

- A first-order scheme for turbulent vertical mixing of momentum and thermodynamic quantities is used within the boundary layer, which can occupy up to the first five layers of the model. Sub-grid-scale gravity wave and orographic drag parameterisations include the impact of orographic variance anisotropy (Gregory et al., 1998). The scheme comprises four elements: (i) "triggering" which determines whether the physical conditions within the grid box constitute convection taking place; (ii) "cloudbase closure" controlling the intensity of convection which is determined by the mass transported through the cloudbase; (iii) a transport model where temperature, moisture, wind fields, and thus precipitation are determined, and (iv) a "convective cloud scheme" where cloud fractions derived from convection are calculated which will be used by the radiation scheme (Grant, 1998).

- In the real world, clouds are formed on scales far below that of the coarse grid used in HadAM3B; therefore, there is the need for a statistical parameterisation of this variable. Probability density functions are used on the total water content over the grid-box mean to parameterise cloud amount/distribution and longevity (Bushell, 1998). Clouds are modelled as either water, ice, or mixed phase when the temperature in the model level is between 0 and $-9{ }^{\circ} \mathrm{C}$. Clouds form when the mean plus the standard deviation of the grid-cell moisture content exceeds a threshold of relative humidity (see RHCrit in Table 1 for numerical values). This cloud water content can then be used to produce a cloud fraction for each grid box (Bushell, 1998). The threshold of total water content for precipitation to occur varies between land and ocean cells to account for the different levels of available cloud condensation nuclei. The scheme uses temperature through the vertical levels to determine the ice and water phases to determine cloud water content.

- Radiation is represented using the radiation scheme of Edwards and Slingo (1996). This scheme has six shortwave and eight long-wave bands and represents the ef- fects of water vapour, carbon dioxide, ozone, and minor trace gases. A background aerosol climatology following Cusack et al. (1998) increases the atmospheric absorption of short-wave radiation relative to previous versions, representing a significant improvement. The long-wave and short-wave spectral scheme used ("3A" of Ingram et al., 1997) is an improvement over the previous versions as it allows the freedom of choices of cloud parameterisation, gases, and aerosols to be included through spectral input files (Edwards, 1998).

- Horizontal diffusion takes the form $k \nabla^{N}$ where both $k$ and $N$ can vary with vertical levels and with variable. The standard resolution of the model uses a formulation $k_{1} \nabla^{6}$ where $k_{1}=5.47 \times 10^{8} \mathrm{~m}^{6} \mathrm{~s}^{-1}$ corresponding to a e-folding timescale for the two-grid wave of approximately $12 \mathrm{~h}$. The topmost level in the model uses a stronger diffusion of the form $k_{2} \nabla^{2}$ where $k_{2}=4.0 \times$ $10^{6} \mathrm{~m}^{2} \mathrm{~s}^{-1}$. Moisture also has stronger diffusion in the five levels below the top (approximately from $150 \mathrm{hPa}$ ) corresponding to $k_{m} \nabla^{4}$ where $k_{m}=1.5 \times 10^{8} \mathrm{~m}^{4} \mathrm{~s}^{-1}$. The functional form and strength of diffusion for other resolutions are summarised in Table 1.

Boundary conditions for the model include the land-sea mask, orography, and its sub-grid-scale variability (originally derived from the US Navy updates 10' dataset), and a range of soil and vegetation parameters (originally derived from data in Wilson and Henderson-Sellers (1985). The model also needs to be initialised with soil moisture and snow cover (based on Willmott et al., 1985), and deep soil temperatures (empirically derived using Warrilow, 1986). When the model is run in atmosphere-only mode, i.e. HadAM3B, sea surface temperature and sea ice (concentration and depth) are required to be prescribed. These can be derived from observational data or from coupled model simulations.

\subsection{Ocean}

The ocean component has a horizontal resolution of $288 \times$ 144 grid points $\left(1.25^{\circ} \times 1.25^{\circ}\right)$ (Gordon et al., 2000) and, as with the atmosphere, also uses Fourier filtering at high latitudes. The higher resolution means that six ocean grid cells correspond to each atmosphere grid cell. In order to simplify the coupling of the atmosphere and ocean models, the landsea mask is defined at the atmosphere resolution; therefore, the ocean model's coastlines appear relatively coarse. In the vertical there are 20 depth levels with finer definition at the ocean surface, with the topmost model layer being $10 \mathrm{~m}$ thick and the bottommost $616 \mathrm{~m}$ thick. The ocean time step is $1 \mathrm{~h}$. The ocean and atmosphere modules are coupled once a day with no flux adjustment necessary.

The ocean model is based on the model of Cox (1984) and is a full primitive equation, three-dimensional model of the ocean. A second-order numerical scheme is used along with centred advection to remove non-linear instabilities. 
Table 1. Summary of the key differences between model variants. For further details of these differences and description of the features common to all variants, see the relevant sections of the text. Note that HadAM3B is identical to the atmosphere of HadCM3B.

\begin{tabular}{|c|c|c|c|c|c|c|}
\hline Item & HadCM3B & HadCM3BL & FAMOUS & HadAMB3 & HadAM3BH & HadRM3B \\
\hline \multicolumn{7}{|l|}{ Atmosphere } \\
\hline Horizontal resolution $(n)$ & $96 \times 73$ & $96 \times 73$ & $48 \times 37$ & $96 \times 73$ & $288 \times 217$ & $\begin{array}{l}\text { Varies with selected } \\
\text { region }\end{array}$ \\
\hline Horizontal resolution (deg) & $3.75^{\circ} \times 2.5^{\circ}$ & $3.75^{\circ} \times 2.5^{\circ}$ & $7.5^{\circ} \times 5^{\circ}$ & $3.75^{\circ} \times 2.5^{\circ}$ & $1.25^{\circ} \times 0.83^{\circ}$ & $\begin{array}{l}0.4425^{\circ} \times 0.4425^{\circ} \\
\text { or } 0.22^{\circ} \times 0.22^{\circ}\end{array}$ \\
\hline Vertical resolution & 19 levels & 19 levels & 11 levels & 19 levels & 30 levels & 19 levels \\
\hline Time step (mins) & 30 & 30 & 60 & 30 & 10 & 5 or 2 \\
\hline Dynamics sweeps/physics time step & 1 & 1 & 1 or 2 & 1 & 2 & 1 \\
\hline Max wind test for half time step dynamics $\left(\mathrm{m} \mathrm{s}^{-1}\right)$ & - & - & - & - & 240 & - \\
\hline Convective precipitation grid-box fraction (conv_eps) & 0.3 & 0.3 & 0.3 & 0.3 & 0.3 & 0.65 or 1.0 \\
\hline Large-scale precipitation grid-box fraction (1s_eps) & 1.0 & 1.0 & 1.0 & 1.0 & 1.0 & 0.75 or 1.0 \\
\hline Boundary layer top and number of levels (eta/level) & $0.835 / 5$ & $0.835 / 5$ & $0.9 / 3$ & $0.835 / 5$ & $0.8 / 6$ & $0.835 / 5$ \\
\hline Cloud levels (eta/level) & $0.02 / 18$ & $0.02 / 18$ & $0.125 / 10$ & $0.02 / 18$ & $0.02 / 29$ & $0.02 / 18$ \\
\hline Pure pressure level start (eta/level) & $0.04 / 17$ & $0.04 / 17$ & $0.06 / 11$ & $0.04 / 17$ & $0.04 / 28$ & $0.04 / 17$ \\
\hline Gravity wave drag start (eta/level) & $0.956 / 3$ & $0.956 / 3$ & $0.9 / 3$ & $0.956 / 3$ & $0.956 / 3$ & $0.956 / 3$ \\
\hline Surface gravity wave constant (m) & $2.0 \times 10^{4}$ & $2.0 \times 10^{4}$ & $2.0 \times 10^{4}$ & $2.0 \times 10^{4}$ & $1.6 \times 10^{4}$ & $2.0 \times 10^{4}$ \\
\hline Trapped lee wave constant $\left(\mathrm{m}^{-3 / 2}\right)$ & $3.0 \times 10^{5}$ & $3.0 \times 10^{5}$ & $3.0 \times 10^{5}$ & $3.0 \times 10^{5}$ & $2.4 \times 10^{5}$ & $3.0 \times 10^{5}$ \\
\hline Filtering safety multiplying factor & 0.01 & 0.01 & 0.011 & 0.01 & 0.1 & - \\
\hline Filtering wave numbers checked every & 1 time step & 1 time step & 1 time step & 1 time step & $6 \mathrm{~h}$ & - \\
\hline Steep slope horizontal diffusion off until pressure level $(\mathrm{kPa})$ & 20 & 20 & 20 & 20 & 20 & 50 \\
\hline Diffusion coefficient $\left(\mathrm{m}^{6} \mathrm{~s}^{-1}\right)^{*}$ & $5.47 \times 10^{8}$ & $5.47 \times 10^{8}$ & $4.19 \times 10^{9}$ & $5.47 \times 10^{8}$ & $4.0 \times 10^{7}$ & $1.7 \times 10^{7}$ \\
\hline Diffusion power (dimensionless) ${ }^{*}$ & 6 & 6 & 8 & 6 & 4 & 4 \\
\hline Humidity diffusion coefficient $\left(\mathrm{m}^{6} \mathrm{~s}^{-1} / \mathrm{m}^{4} \mathrm{~s}^{-1}\right)^{*}$ & $\begin{array}{l}5.47 \times 10^{8} \\
1.5 \times 10^{8}\end{array}$ & $\begin{array}{l}5.47 \times 10^{8} \\
1.5 \times 10^{8}\end{array}$ & $2.4 \times 10^{8}$ & $\begin{array}{l}5.47 \times 10^{8} \\
1.5 \times 10^{8}\end{array}$ & $\begin{array}{l}2.0 \times 10^{7} \\
4.0 \times 10^{7}\end{array}$ & $1.7 \times 10^{7}$ \\
\hline Humidity diffusion power (dimensionless) ${ }^{*}$ & $\begin{array}{l}6 \\
4\end{array}$ & $\begin{array}{l}6 \\
4\end{array}$ & 4 & $\begin{array}{l}6 \\
4\end{array}$ & 4 & 4 \\
\hline RHcrit* & $\begin{array}{l}0.95 \\
0.7\end{array}$ & $\begin{array}{l}0.95 \\
0.7\end{array}$ & $\begin{array}{l}0.91 \\
0.687\end{array}$ & $\begin{array}{l}0.95 \\
0.7\end{array}$ & $\begin{array}{l}0.95 \\
0.8\end{array}$ & $\begin{array}{l}0.91 \\
0.84 \\
0.95\end{array}$ \\
\hline \multicolumn{7}{|l|}{ Ocean } \\
\hline Horizontal resolution $(n)$ & $288 \times 144$ & $96 \times 73$ & $96 \times 73$ & - & - & - \\
\hline Horizontal resolution (deg) & $1.25^{\circ} \times 1.25^{\circ}$ & $3.75^{\circ} \times 2.5^{\circ}$ & $3.75^{\circ} \times 2.5^{\circ}$ & & & \\
\hline Vertical resolution & 20 levels to $5500 \mathrm{~m}$ & 20 levels to $5500 \mathrm{~m}$ & 20 levels to $5500 \mathrm{~m}$ & - & - & - \\
\hline North Atlantic bathymetry & $\begin{array}{l}\text { Standard Met } \\
\text { Office }\end{array}$ & No Iceland & No Iceland & - & - & - \\
\hline Vertical tracer diffusivity & $\begin{array}{l}\text { Richardson number } \\
\text { dependence }\end{array}$ & $\begin{array}{l}\text { Constant } \\
\text { background value }\end{array}$ & $\begin{array}{l}\text { Constant } \\
\text { background value }\end{array}$ & - & - & - \\
\hline Coefficient for solar penetration (ratio) & 0 & $3.8 \times 10^{-1}$ & $3.8 \times 10^{-1}$ & - & - & - \\
\hline Horizontal momentum diffusion coefficient $\left(\mathrm{m}^{2} \mathrm{~s}^{-1}\right)$ & $3 \times 10^{3}$ & $1.5 \times 10^{5}$ & $1.5 \times 10^{5}$ & - & - & - \\
\hline Isopycnal diffusion coefficients $\left(\mathrm{m}^{2} \mathrm{~s}^{-1}\right)$ & $\begin{array}{l}\text { Visbeck et al. } \\
\text { (1997) latitudinally } \\
\text { varying scheme }\end{array}$ & Constant values & Constant values & - & - & - \\
\hline Sea ice diffusion $\left(\mathrm{m}^{2} \mathrm{~s}^{-1}\right)$ & $6.7 \times 10^{2}$ & $2.0 \times 10^{3}$ & $2.0 \times 10^{3}$ & - & - & - \\
\hline
\end{tabular}

The Arakawa B-grid is used for staggering of tracer and velocity variables, allowing for more accurate numerical calculations of geostrophically balanced motion. It uses a rigid lid which eliminates fast external mode gravity waves found in the real ocean, thus allowing for longer time steps, and with the result that there is no variation in the volume of the ocean. The barotropic solver requires the pre-specification of "islands" around which the barotropic circulation may occur (see Sect. 4.1.5).

As with the atmosphere, the ocean model also requires a number of parameterisations.

- The ocean mixed layer is represented by the Kraus and Turner (1967) model which assigns $15 \%$ of gravitational potential energy and $70 \%$ of wind-stress energy to turbulent kinetic energy, which is mixed out exponentially with depth. At all depths, five iterations of convective mixing are carried out at each time step. Tracer and momentum mixing is modelled using the K-theory scheme. Within the mixed layer a simplified version of the Large et al. (1994) scheme is employed: below this the Pacanowski and Philander (1981) K-theory parameterisation is used.

- Momentum mixing is approximated using diffusion that is governed by a coefficient that consists of two terms: a constant background value and a term dependent on the local Richardson number. For tracers, diffusion increases with depth as detailed in Table A of Gordon et al. (2000).

- Horizontal eddy mixing of tracers is carried out using the isopycnal parameterisation of Gent and McWilliams (1990), with thickness diffusion coefficients modified following the method of Visbeck et al. (1997). Isopycnal mixing uses the Griffies et al. (1998) implementation of the Redi (1982) scheme. The along-isopycnal diffusion coefficient is $1000 \mathrm{~m}^{2} \mathrm{~s}^{-1}$. Horizontal mixing of momentum is performed using a latitudinally varying formulation which, coupled with the finer resolution of the ocean grid, enables western boundary currents to be resolved. 
Table 2. Availability of alternative land surface schemes.

\begin{tabular}{lllllll}
\hline Item & HadCM3B & HadCM3BL & FAMOUS & HadAM3B & HadAM3BH & HadRM3B \\
\hline MOSES1 & HadCM3B-M1 & HadCM3BL-M1 & FAMOUS-M1 & HadAM3B-M1 & HadAM3BH-M1 & HadRM3B-M1 \\
MOSES2.1 & HadCM3B-M2.1 & HadCM3BL-M2.1 & - & HadAM3B-M2.1 & HadAM3BH-M2.1 & $*$ \\
MOSES2.1 TRIFFID (D and E) & HadCM3B-M2.1 & HadCM3BL-M2.1 & - & HadAM3B-M2.1 & HadAM3BH-M2.1 & $*$ \\
MOSES2.2 & HadCM3B-M2.2 & HadCM3BL-M2.2 & FAMOUS-M2.2 & $*$ & $*$ & $*$ \\
MOSES2.2 TRIFFID (D and E) & HadCM3B-M2.2 & HadCM3BL-M2.2 & FAMOUS-M2.2 & $*$ & $*$ & $*$ \\
\hline
\end{tabular}

* Variant currently does not exist, but there is no barrier to creation.

Table 3. Computational performance of M1 configurations.

\begin{tabular}{|c|c|c|c|c|c|c|}
\hline & HadCM3B-M1 & HadCM3BL-M1 & FAMOUS-M1 & HadAM3B-M1 & HadAM3BH-M1 & HadRM3B-M1 \\
\hline Cores & 16 & 16 & 8 & 16 & 64 & 16 \\
\hline Speed (model years/day) & 47 & 85 & 450 & 109 & 5 & 6 \\
\hline Cost (model years/day/core) & 3.0 & 5.3 & 56.3 & 6.8 & 0.07 & 0.4 \\
\hline
\end{tabular}

- There is no dynamic connection between the Mediterranean Sea and Atlantic Ocean, so it is modelled as a "diffusive pipe" by completely mixing the easternmost point of the Atlantic with the westernmost point of the Mediterranean. Mixing occurs over the top 13 layers, to a depth of $1200 \mathrm{~m}$, on the assumption that Mediterranean water will sink to at least this depth. A similar parameterisation is applied in the outflow of Hudson Bay.

- Ice sheets are not modelled dynamically; therefore, the snow accumulation on surface land ice points and over isolated water bodies must be balanced by loss through a notional iceberg calving that is represented as a timeinvariant freshwater flux (which, because of the rigid lid, is converted to a virtual salinity flux). This is distributed around the edge of the ice sheets and polar oceans. The virtual salinity flux is calculated using a globally constant reference salinity, which can distort the local response to the surface water forcing. River runoff is instantaneously transferred to the ocean using a prescribed runoff map.

The modern bathymetry for the model is derived from the ETOPO5 reconstruction (Edwards, 1989) using a simple smoothing algorithm. The geometry of some significant channels is modified from the resulting coarse interpolation to ensure a more realistic model performance (Gordon et al., 2000). For example, the Greenland-Scotland Ridge and Denmark Strait have significant sub-grid-scale channels which are lost in the smoothing and so have been re-created by deepening channels (single cell width) in three locations along the ridge to reproduce the mean outflow to match observations, and the bathymetry around Indonesia is modified to ensure that flow occurs between Indonesia and Papua New Guinea but not between Indonesia and the mainland of Asia.

\subsection{Sea ice}

Sea ice is calculated as a zero layer model on top of the ocean grid. Partial cell coverage of sea ice is possible up to 0.995 in the Arctic and 0.98 in the Antarctic. This is based on the parameterisation of sea ice concentration from Hibler (1979). Ice forms primarily by freezing in leads, although ice can also form from snow falling on existing ice. It is assumed to freeze at the base of the sea ice at the freezing point of $-1.8^{\circ} \mathrm{C}$. A constant salinity is assumed for ice, with the excess salt on melting/formation added as a flux into the ocean. Sea ice dynamics are simply parameterised: the surface wind stress over sea ice is applied to the ocean beneath the ice, and the ice thickness, concentration, and accumulated snow then drift following the ocean currents in the top model layer (Gordon et al., 2000). The maximum depth that sea ice can reach due to convergence from drift is limited to $4 \mathrm{~m}$ in depth, although it may subsequently thicken further due to freezing. The albedo of sea ice is set at 0.8 for temperatures below $-10^{\circ} \mathrm{C}$ and 0.5 for temperatures above $0{ }^{\circ} \mathrm{C}$, with a linear variation between these values.

\subsection{Land surface scheme: MOSES1}

The MOSES (Met Office Surface Exchange Scheme) land surface scheme is built upon the previous Met Office land surface scheme (UKMO) (Warrilow and Buckley, 1989). In the Gordon et al. (2000) version of HadCM3, MOSES version 1, MOSES1, is used. A technical overview of MOSES1, a comparison to its predecessor (UKMO) and its climatological impact are provided by Cox et al. (1999).

In addition to calculating the fluxes of water and energy, MOSES1 incorporates the physiological impact of atmospheric carbon dioxide, water vapour, and temperature on photosynthesis and stomatal conductance. It accounts for the effects of freezing and melting of soil moisture in four soil layers, the proportion of frozen soil moisture being a function of the soil heat capacity and conductivity of the grid 
cell. Both vegetated and non-vegetated land surface types are characterised by a set of surface properties that are not updated during the model run. The canopy scheme is based on that used in Warrilow (1986).

MOSES1 has two sets of prescribed land surface property attributes, which are input into the model via two external files. The soil attributes are volumetric soil moisture concentration at the wilting point, critical point, field capacity, and saturation, the saturated hydrological soil conductivity, the Clapp-Hornberger B exponent, the thermal capacity of soil, thermal conductivity of soil, and the saturated soil water suction. (The Clapp-Hornberger exponent is a measure of the pore volume distribution and the formulation was originally devised in Brooks and Corey, 1964.) The vegetation attributes are root depth, snow-free albedo, stomatal resistance to evaporation, surface roughness, canopy water capacity, infiltration enhancement rate, deep snow albedo, leaf area index, and canopy height of vegetation fraction. All of these attributes are derived from the Wilson and Henderson-Sellers (1985) dataset.

\section{Alternative land surface schemes}

Section 2.5 describes the MOSES1 land surface scheme which is used in the standard version of HadCM3. Here we describe two other versions, MOSES2.1 and MOSES2.2, as well as the vegetation component TRIFFID.

\subsection{MOSES2}

MOSES1 requires maps of vegetation properties, such as root depth and leaf area index, to be prescribed (normally in a set of external files). As such, it is not very suitable for an interactive vegetation model. As part of the process of developing a dynamic vegetation module for HadCM3, an upgraded land surface scheme, MOSES2, was also developed. The first version of this scheme, MOSES2.1, is the original scheme used in early work with dynamic vegetation (Cox et al., 2000). This version was originally coupled to HadCM3LC (Cox et al., 2000), which is a flux-corrected low-resolution version of HadCM3 which includes a carbon cycle. MOSES2.1 was further developed for use in HadCM3 as part of the Paleoclimate Modelling Intercomparison Project Phase II (PMIP2) (Braconnot et al., 2007). Subsequently, a second version of MOSES2 was developed, MOSES2.2 (Essery et al., 2001, 2003), which was similar scientifically to MOSES2.1 but had improved code structure. This has become the initial core of the JULES land surface model (Best et al., 2011; Clark et al., 2011). At the University of Bristol, we have mainly used MOSES2.1, with MOSES2.2 only being used in a few specific contexts such as for investigating changes in atmospheric chemistry (Valdes et al., 2005; Beerling et al., 2011) because it can include additional parameterisations of isoprene emissions. MOSES2.2 can also be used in FAMOUS
(Williams et al., 2013), though the majority of FAMOUS publications have used MOSES1.

A detailed discussion of the upgrades between MOSES1 and MOSES2.2 is provided in Essery et al. (2003) and a full and complete technical overview of MOSES2.2 in Essery et al. (2001). But so far there have been no clear comparisons as to how MOSES2.2 differs scientifically or technically from MOSES2.1, despite MOSES2.1 being the core version used at Bristol. The following sections aim to rectify this and clarify the differences between MOSES2.2 and MOSES2.1. First we outline how MOSES2.2 differs from MOSES1.

\subsubsection{Differences between MOSES2.2 and MOSES1}

Compared to MOSES1, MOSES2.2 has major upgrades to all aspects of the land surface exchange and the surface radiation scheme Essery et al. (2003). The surface radiation scheme has an updated coupling between the land surface and atmosphere, including the calculation of surface net radiation and surface heat and moisture fluxes. MOSES2.2 allows fractional coverage of different surface types on a subgrid scale. There are nine land surface types explicitly modelled at a sub-grid scale, each with a set of characteristic parameters. MOSES2.2 can be fully coupled to the TRIFFID dynamic vegetation model (see Sect. 3.2) via the five plant functional types (PFTs): broadleaf trees, needleleaf trees, shrubs, C3 (temperate) grasses, and C4 (tropical) grasses. The remaining four are non-vegetated surface types: urban, inland water, bare soil, and ice. Excluding ice type, each land surface grid box can be made up of any mixture of the other eight surface types. Land ice must have a fractional cover of 0 or 1 only. The fractional coverage for each surface type is specified for each grid point from an external file. In addition, another file is supplied specifying the necessary parameters for the five vegetation types at each grid point: leaf area index (LAI), canopy height, and canopy conductance (not PFT dependent). The vegetation fractions and parameters will be updated by TRIFFID if it is being used. Other PFT-dependent parameters, including root depth and values of albedo under a variety of conditions, are hard-wired into the code.

In MOSES1, the surface energy and moisture fluxes are calculated based on grid-box average values of parameters (such as roughness and length). In MOSES2.2, the surface energy balance is explicitly solved for each surface type and then weighted by the fractional area of the surface types within the grid box. This produces the grid-box average surface temperature and soil moisture and fluxes of longwave, short-wave, sensible, latent, and ground heat. Above the surface, air temperature, humidity, and wind speed on atmospheric levels are treated as homogeneous across the grid box. Similarly, soil temperatures and moisture contents are also treated as homogeneous. The aerodynamic surface roughness lengths are calculated explicitly according to the canopy height and the rate of change of roughness length 
with canopy height for each tile. This roughness length is used to calculate surface-atmosphere fluxes of heat, water, momentum, and $\mathrm{CO}_{2}$. The surface albedo determines the amount of downward short-wave heat flux that is reflected at the surface. The surface albedo for fractional covered vegetated surface types (unweighted) is described by the snowfree and cold deep snow albedos. The soil albedo is defined according to colour and moisture content. LAI is also used in determining the surface albedo for surfaces covered by vegetation.

The hydrological cycle in MOSES2.2 is similar to MOSES1, with small changes for the interactions with vegetation. However, it continues to treat each tile separately, so extraction of water from the soil is calculated for each tile and then weighted summed to give the grid-box average. Precipitation is partitioned into interception (via the canopy), throughfall, runoff, and infiltration into the ground. Different parameters apply to each vegetation type. Canopy water refers to the precipitation intercepted by plant leaves available for free evaporation. MOSES2 uses the same four soil layers as MOSES1, with thicknesses from the surface downwards set to $0.1,0.25,0.65$, and $2 \mathrm{~m}$. The moisture content of the upper soil layer $(0.1 \mathrm{~m})$ is increased via snowmelt and throughfall and decreased according to evaporation from the soil layer, flow of water into lower layers, and draw-up of water via plant roots. The extraction of water from any particular soil layer is proportional to the water lost by evapotranspiration, reflecting the vertical distribution of roots. The five PFTs have different root depths, such that trees are able to access moisture from soil layers at deeper depths compared with grasses and shrubs. The soil moisture content and soil water phase changes and the associated latent heat describe the thermal characteristics of soil that determine, via a discretised form of the heat diffusion equation, the subsurface temperatures. Subsurface soil temperatures are determined by the diffusive heat fluxes into and out of a soil layer and the heat flux advected from the layer by the moisture flux.

MOSES2 requires similar soil parameter inputs to MOSES1, although it additionally requires bare soil albedo and soil carbon content of the soils. However, the vegetation properties are very different. MOSES1 required inputs of grid-box average LAI, root depth, etc., whereas MOSES2 requires prescribed inputs of the fractional types of each surface type, the LAI and canopy height of each vegetated PFT, and the overall canopy conductance. It also includes a disturbance fraction that represents agriculture. When using dynamic vegetation (TRIFFID), these fields (except for disturbance) are only used for initialisation and the model will dynamically update them.

\subsubsection{Differences between MOSES2.2 and MOSES2.1}

There are a number of key differences between MOSES2.1 and MOSES2.2, and a number of smaller modifications be- tween the versions. These major changes include the following.

- MOSES2.2 uses a spectral albedo scheme to calculate separately the diffuse and direct-beam surface albedos. This scheme is not used in MOSES2.1, although modifications can be added to include it.

- MOSES2.2 uses a spectral snow albedo model that includes a prognostic grain size that characterises the ageing of snow and its impact on snow albedo. This is not present in MOSES2.1.

- MOSES2.2 also introduces a new calculation of evapotranspiration from soil moisture stores, as well as a different parameterisation of bare soil evaporation.

- Supersaturation in the soil layer is treated differently in the two versions of MOSES2. In MOSES2.2, supersaturation results in an increase in surface runoff. In contrast, supersaturation in MOSES1 and MOSES2.1 is managed via an increase in downward flow into the deeper soil layers and so is removed via subsurface runoff.

Tests carried out in which MOSES2.1 is gradually changed to MOSES2.2 show that the first two changes affect surface temperature, whereas the third difference substantially alters soil moisture. Supersaturation changes impact the partitioning of runoff between surface and sub-surface and also influence the soil moisture, and to a lesser extent the evapotranspiration changes.

There are also a number of smaller changes (such as using an implicit soil moisture scheme in MOSES2.2 compared to an explicit scheme in MOSES2.1 and MOSES1), but these do not result in a major change to the climate. MOSES2.2 also had some major restructuring of the Fortran code.

Additionally, in the default version of MOSES2.1 (used until recently), the rate of respiration increases almost exponentially with temperature (Julia C. Tindall, personal communication, 2015). As a result, in some conditions such as during the Amazon dry season, respiration excessively increases, and this decreases soil moisture, which consequently inhibits tree growth. In MOSES2.2, the impact of temperature on respiration rate declines at high temperatures. This revised respiration rate reduces drying and dieback of trees. This has a relatively limited impact on the simulation of vegetation for the pre-industrial (the broadleaf tree fraction is slightly increased in the Amazon), but does have a bigger effect on very warm climates such as the early Eocene. This has now become the default for the Bristol variant and will be referred to as HadCM3B-M2.1a.

\subsection{TRIFFID}

MOSES2.1 and MOSES2.2 both have the capacity to be run in coupled mode with a dynamic vegetation and terrestrial 
carbon cycle scheme, TRIFFID (Top-down Representation of Interactive Foliage and Flora Including Dynamics) (Cox et al., 1998; Cox, 2001). TRIFFID predicts the distribution and properties of global vegetation based on plant functional types using a competitive, hierarchical formulation. The performance and sensitivity of TRIFFID have been compared with a variety of other dynamic vegetation models (Sitch et al., 2008) and an updated version of TRIFFID is used in both the latest Coupled Model Intercomparison Project (CMIP5) model HadGEM2-ES (Collins et al., 2011) and in JULES (Clark et al., 2011).

In the model configurations presented here, TRIFFID is normally only used with MOSES 2.1 because of a dry bias in MOSES2.2 which is manifested by an overly dry surface climate over the Eurasian continent in summer. This results in loss of vegetation if used with dynamic vegetation. The cause of this drying is unclear, but is partially linked to the changes in evaporation and evapotranspiration parameterisations discussed above.

TRIFFID updates the five vegetation PFTs and the bare soil fraction, all of which can change dynamically. TRIFFID can be run in two different modes.

- Equilibrium mode, where TRIFFID runs for 50 years of TRIFFID for each 5 years of the climate model run. The fluxes between the land and the atmosphere are calculated and averaged over 5 years. This is particularly valuable for quick spin-up of the vegetation and soil carbon.

- Dynamic mode, where TRIFFID is run every 10 days. Fluxes are averaged over 10 days; as such highfrequency variability is accounted for. This mode is the standard for full runs of the coupled model.

MOSES2 passes the averaged fluxes of carbon to TRIFFID, which calculates the growth and expansion of the existing vegetation, and updates the land surface parameters based on the new vegetation distribution and structure. TRIFFID calculates areal coverage, leaf area index (LAI), and canopy height for five defined plant functional types (PFTs): broadleaf tree, needleleaf tree, $\mathrm{C} 3$ grass, $\mathrm{C} 4$ grass, and shrub. These PFTs respond differently to climate and $\mathrm{CO}_{2}$ forcing (e.g. $\mathrm{C} 3$ and $\mathrm{C} 4$ grasses use different photosynthetic pathways) and also impact differently on the physical properties of the land surface, i.e. possessing different aerodynamic roughness lengths and albedo properties. Broadleaf and needleleaf trees and $\mathrm{C} 3$ and $\mathrm{C} 4$ grasses react independently within the model due to their unique parameter sets. $\mathrm{C} 4$ plants use water more efficiently than $\mathrm{C} 3$ plants, requiring less water to produce the same amount of biomass. Overall, C4 plants have the highest critical humidity deficit and temperature range, meaning that in high-temperature, lowmoisture environments they will do better than other PFTs, even though the competition model would normally favour trees.
All PFTs can co-exist within the same grid box, each possessing a fractional coverage that is equivalent to the population size. The fractional coverage co-existence approach allows smooth transitions to occur when the vegetation distribution changes rather than the sudden discontinuities that would occur in a "dominant" PFT-only approach (Svirezhev, 2000). However, the Lotka-Volterra equations used in TRIFFID mean that each grid cell in the model tends to converge on one dominant plant functional type (Hughes et al., 2006). Competition is essentially based on a height hierarchy of trees $>$ shrubs $>$ grasses. Each terrestrial grid square has a small minimum content of each plant functional type, regardless of location and competition, as a "seeding" fraction (Cox, 2001). This ensures that no PFT can become extinct and can regenerate when conditions become appropriate. TRIFFID can specify areas of agricultural crops as C3 and $\mathrm{C} 4$ grasses, without competing land types (Cox, 2001).

The terrestrial net primary productivity (NPP) is calculated by a coupled photosynthesis-stomatal conductance model (Cox et al., 1998). Factors affecting the rate of photosynthesis are the humidity deficit, the photochemically active radiation, soil moisture, and LAI. The maximum rate of photosynthesis is directly related to the leaf temperature and the upper and lower temperatures for photosynthesis (defined individually for each PFT). Carbon is stored in the vegetation and soil stores.

The predicted vegetation in each grid box feeds back into the climate system in a number of ways, principally through evapotranspiration from the canopy, alteration of surface albedo, and alteration of mixing at the boundary layer between the surface and the atmosphere (due to changes in roughness length).

\section{Variants with differing resolutions}

\subsection{HadCM3BL}

HadCM3BL comprises the same model components as HadCM3B, but with a lower-resolution ocean which matches the standard atmosphere resolution of $96 \times 73$ grid points $\left(3.75^{\circ} \times 2.5^{\circ}\right)($ Cox et al., 2000). Note that the Bristol version, HadCM3BL, is very different from the Met Office version. The Met Office version was mainly used for the early carbon cycle work (Cox et al., 2000), but required significant flux corrections to ensure that the Atlantic surface climate was reasonable. Our version does not require flux correction because of changes in bathymetry described below. It can be run with all versions of MOSES, with or without TRIFFID, in the same manner as HadCM3B. We tend to use HadCM3BL when long simulations are required. For instance, when the land-sea mask and/or bathymetry are substantially changed from those of modern ones, it can take many thousands of years of integration to get the deep ocean into equilibrium. As such, HadCM3BL has been used exten- 
sively for our pre-Quaternary climate modelling work (e.g. Marzocchi et al., 2015b; Bradshaw et al., 2015; Kennedy et al., 2015; Loptson et al., 2014).

The implementation of the atmosphere and land surface schemes is identical to HadCM3B. There are some differences in the ocean due to its lower resolution, some of which are substantive differences required either to maintain stability or to reproduce the present-day climate without the need for the flux corrections used in earlier versions of the model, some of which are simple scalings of parameters to give the same scientific behaviour as HadCM3B at the lower resolution. These differences between HadCM3B and HadCM3BL, which are described below, are generally consistent with work done to optimise the FAMOUS model (Jones, 2003), which has the same ocean resolution as HadCM3BL.

\subsubsection{North Atlantic bathymetry: "No Iceland"}

As described in Sect. 2.3, care was taken when developing HadCM3 to define the bathymetry of the North Atlantic in order to ensure that the appropriate flow through the Denmark Strait was captured. This flow is lost when the ocean resolution is reduced in HadCM3BL as the channel between Iceland and Greenland becomes less than a single grid cell wide (on the velocity grid) and thus no flow is permitted. Jones (2003) investigated potential modifications to allow increased heat transport through this region, thus alleviating the unrealistic build-up of sea ice in the Nordic Sea, and concluded that the removal of Iceland was the preferred solution. With this modification, the improved meridional overturning circulation leads to more realistic heat transports in the coupled system and alleviates the need for flux correction.

This change also has a knock-on effect on the land surface (and ultimately the atmosphere) in that the two cells that define Iceland have been removed.

\subsubsection{Ocean vertical diffusion}

In HadCM3BL, the Richardson number dependence of the vertical tracer diffusivity is replaced with a constant background rate, as it is in FAMOUS. Jones (2003) describes problems encountered with FAMOUS in the interaction between the mixed layer and deep vertical diffusion schemes, but this was found to have little impact on the solution because of the relatively low resolution.

For the calculation of vertical diffusion, HadCM3BL uses a different calculation for the density of seawater from HadCM3B. HadCM3B calculates all densities relative to a reference level at the surface using the updated equation of state for seawater of UNESCO (1981). This can result in negative density gradients in the deep ocean and hence a negative Richardson number, which in turn can produce very high diffusivities at depth which Pacanowski and Philander (1981) was never intended to handle (Rickard, 1999). HadCM3BL instead derives Bryan and Cox (1972) third-order polynomi- als for each $250 \mathrm{~m}$ depth span of the ocean (Foreman, 2005) to fit the Knudsen-Ekman equation for the density of seawater and does not produce negative density gradients (Rickard, 1999), but the range of salinities covered may be insufficient for some applications. This choice of diffusion scheme is consistent with that used in FAMOUS.

\subsubsection{Ocean isopycnal diffusion}

HadCM3BL uses different coefficients for a number of aspects of the diffusion formulation, as described in Table 1. All of these values are consistent with those used in FAMOUS. In addition, the Visbeck et al. (1997) scheme for the calculation of isopycnal thickness diffusion coefficients, introduced in HadCM3B to improve resolution of currents such as western boundary currents on the $1.25^{\circ}$ grid, is not used in HadCM3BL. Instead, fixed values of the coefficients for surface ocean diffusion, deep ocean diffusion, and scale depth are specified, as in FAMOUS.

\subsubsection{Solar penetrative radiation}

In HadCM3 the penetration of solar radiation is represented by a double exponential decay with depth, with coefficients determined from observations. The ratio between the shallower decay and deeper decay exponential is controlled by a parameter called RSOL. This is set to 0.0 in HadCM3B and is set to $3.8 \times 10^{-1}$ in HadCM3BL, as it is in FAMOUS.

\subsubsection{Islands}

HadCM3B defines six islands in the barotropic solution, around which non-zero depth-integrated flow is permitted: Antarctica, Australia, New Zealand, the Caribbean, Madagascar and Iceland. In HadCM3BL, there is no island for Iceland as this is entirely absent from HadCM3BL and Madagascar is also not defined as an island due to its proximity to Africa.

\subsection{HadAM3BH}

HadAM3BH is a higher-resolution version of the atmosphere-only variant, HadAM3B. This model is different to that used by the Met Office (e.g. Hudson and Jones, 2002; Arnell et al., 2003), which keeps to 19 levels in the vertical but has some changes to the parameterisations, particularly in the boundary layer. It is used for studies in which the atmospheric circulation is critical, and as such is best represented at high resolution. Its horizontal resolution is 3 times greater than HadAM3B both latitudinally and longitudinally, i.e. $288 \times 217$ grid points $\left(1.25^{\circ} \times 0.83^{\circ}\right)$. The number of vertical levels is increased from 19 to 30 , with the extra levels being concentrated close to the Earth's surface and the upper levels remaining similar to HadAM3B. The higher spatial resolution requires a smaller time step of $10 \mathrm{~min}$. It may be used with either the MOSES1 or 
MOSES2.1 land surface schemes, and can be used with TRIFFID, though this has rarely been done. The time stepping algorithm is slightly different, in that the dynamics can be updated multiple times between the full physics time steps. In HadAM3BH, we use two dynamic per physics time steps to allow for improved numerical stability of the model. Various diffusion coefficients, critical relative humidity, and parameters for the gravity wave drag scheme have been re-tuned to account for the change in resolution, as documented in Table 1. Otherwise the model has identical physics to HadAM3B and has had no further changes.

\subsection{HadRM3B}

HadRM3B is the regional climate model (RCM) version of HadAM3B which has been used when representation of high-resolution atmospheric processes is important, such as around orography or studying extreme events. It can be configured for any domain size and location has commonly been used for studies over Europe (Jones et al., 1995), the Arctic (Day et al., 2013) and Svalbard (Day et al., 2012), and the East Asian Monsoon region (Bhaskaran et al., 1996). It has also been used to model deep time (Haywood et al., 2004).

The BRIDGE version is based on the same fundamental physics and model structure as the Met Office HadAM3, and currently is only available with the MOSES1 land surface scheme. We again do not make any substantial changes to the physical parameterisations, so the model is largely identical to HadAM3 except for parameters sensitive to resolution.

Regional climate models require either fixed or time evolving data on the large scale and global atmospheric and ocean response to climate forcings to be provided to them at their lateral (atmospheric) and sea surface boundaries, such as potential temperature and specific humidity. The common experiment set-up, used here, is a one-way nested approach, where no information is fed back into the GCM simulation, but the large-scale atmospheric circulation patterns, such as the location of the jet streams, are fed in through the lateral boundary conditions (LBCs). For a RCM to have a "parent" GCM is rare, offering a unique opportunity to investigate the effects of dynamical downscaling without modification (or contradiction) of the physics between the driving GCM and the RCM at the lateral boundaries. LBCs are updated every $6 \mathrm{~h}$ and linearly interpolated for time steps in between. A four-grid smoothing is applied to global model data entering the regional model domain. Therefore, typically, HadRM3B has been run here using HadAM3B or HadCM3B to produce the LBCs, sea surface temperature, and sea ice concentration data, although there have been experiments using SSTs from HadISST and HadGEM as well as other models in the CMIP5 experiment to analyse the sensitivity of the model to its boundary conditions.

HadRM3B is run on a standard lat-lon grid with the pole rotated so that the centre of the domain of interest lies across the Equator within the RCM's grid of reference (see Fig. 1)

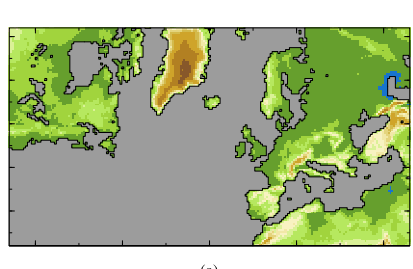

(a)

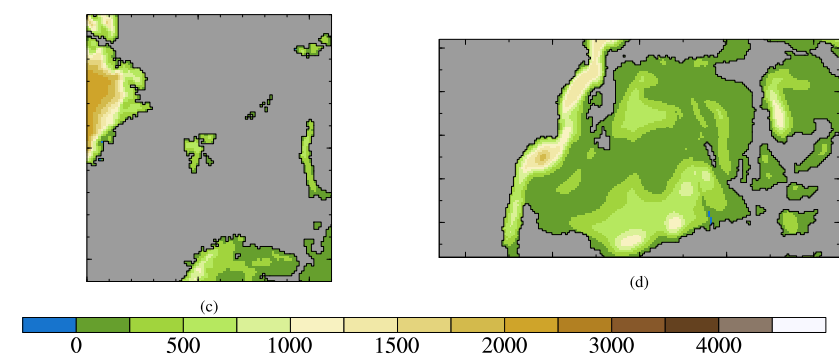

Figure 1. Land-sea mask and orography (sea coloured grey, land height in metres) for four configurations of HadRM3B. (a) shows the standard European domain at $0.44^{\circ}$ resolution, (b) shows the equivalent domain for East Asia, (c) shows a configuration for the Arctic and Svalbard at $0.22^{\circ}$ (as used in Day et al., 2012), and (d) a North America/European configuration for the early Cretaceous at $0.44^{\circ}$ resolution (as used in Haywood et al., 2004).

to reduce variation in the areas of the grid cells. The time step of the model is $5 \mathrm{~min}$ to maintain numerical stability with the increase in spatial resolution which is commonly $0.44^{\circ} \times 0.44^{\circ}(\sim 50 \mathrm{~km} \times 50 \mathrm{~km})$ but has also been run at $0.22^{\circ} \times 0.22^{\circ}(\sim 25 \mathrm{~km} \times 25 \mathrm{~km})$. Lateral boundary conditions are typically provided every $6 \mathrm{~h}$ and linearly interpolated to each time step. The main difference between HadRM3B and HadCM3B/HadAM3B in terms of atmospheric dynamics is in the sub-grid-scale diffusion applied to the horizontal wind component to prevent the accumulation of energy at the smallest scales and noise (see Table 1). In addition, the parameters which control the proportion of a grid box over which convective precipitation and large-scale precipitation are assumed to fall, as well as diffusion parameters, vary compared to HadAM3B (see Table 1, variables conv_eps and 1s_eps).

Simulations using the regional climate models have enabled improved spatial representation of temperature and precipitation patterns and response to climate forcings, particularly around mountains and coastlines. The increase in resolution also improves the simulated temporal variability, including simulation of extremes (Durman et al., 2001).

\section{Comparison with data}

The aim of this section is to qualitatively and quantitatively evaluate the suite of HadCM3@Bristol models in terms of their ability to recreate key aspects of the climate system relative to observations, and other models within the CMIP5 
family. In the following subsections, a selection of observational datasets is compared to multiple modelled climatic variables. Details on the datasets used for each variable are briefly outlined in each subsection. This is not intended to be a complete model evaluation; however, it will highlight that some variants do a more realistic job than others at representing various environmental processes. Where appropriate, stronger or weaker models will be highlighted, and some other CMIP5 models will be shown for comparison. Because much of our work at Bristol involves carrying out palaeoclimate or idealised simulations, our standard control simulations are static pre-industrial simulations, similar to the CMIP5 DECK pre-industrial simulation (Eyring et al., 2016a). However, most observational datasets are from the instrumental record, typically the last few decades. This is to be considered when interpreting our evaluation, although it is likely that differences between the pre-industrial and the instrumental period are generally small relative to the model biases.

A quantitative evaluation (global root-mean square difference (RMSE) analysis) of the four base state BRIDGE models, namely HadCM3B with the MOSES1 land surface scheme, HadCM3B with MOSES2.1a, HadCM3BL with MOSES2.1a, and FAMOUS with MOSES1, is performed against reanalysis and/or observational data and shown alongside new and predecessor models from the CMIP5 database (Fig. 2; BRIDGE models highlighted in red). Here we make use of the ESMValTool(v1.0), a community diagnostic and performance tool (Eyring et al., 2016b) to assess and compare the magnitude of known systematic biases inherent in all climate models. Better understanding of these biases is instrumental in diagnosing their origin and a model's ability to reproduce observed spatial and temporal variability and trends in various atmospheric (e.g. large-scale circulation) and oceanic phenomena (e.g. ENSO). CMIP5 model data are provided from http://www.ceda.ac.uk, while observational (obs4MIPs; Ferraro et al., 2015) and re-analysis (ana4MIPs; Ferraro et al., 2015) data are provided from https://www.earthsystemcog.org, all conforming to the CMIP5 format. Here the BRIDGE models have also been standardised to the CMIP5 format. Further, models and observations are re-gridded to the coarsest resolution within the ESMValTool framework for evaluation. Table 4 details the different metrics used for the evaluation of the historical model simulations in Fig. 2. The BRIDGE models are only pre-industrial climatologies (30 years) without any year-on-year historical forcing; however, this is not expected to be detrimental for the evaluation. The results in Fig. 2 demonstrate that the BRIDGE suite of models, with the exception of FAMOUS-M1H, accurately reproduces observed global spatio-temporal patterns. Indeed, HadCM3BM1, HadCM3B-M2.1a, and in most respects HadCM3BLM2.1a, outperform many of the higher-fidelity CMIP5 models with lower RMSE when compared to the observations, particularly with respect to global air temperature (at 850

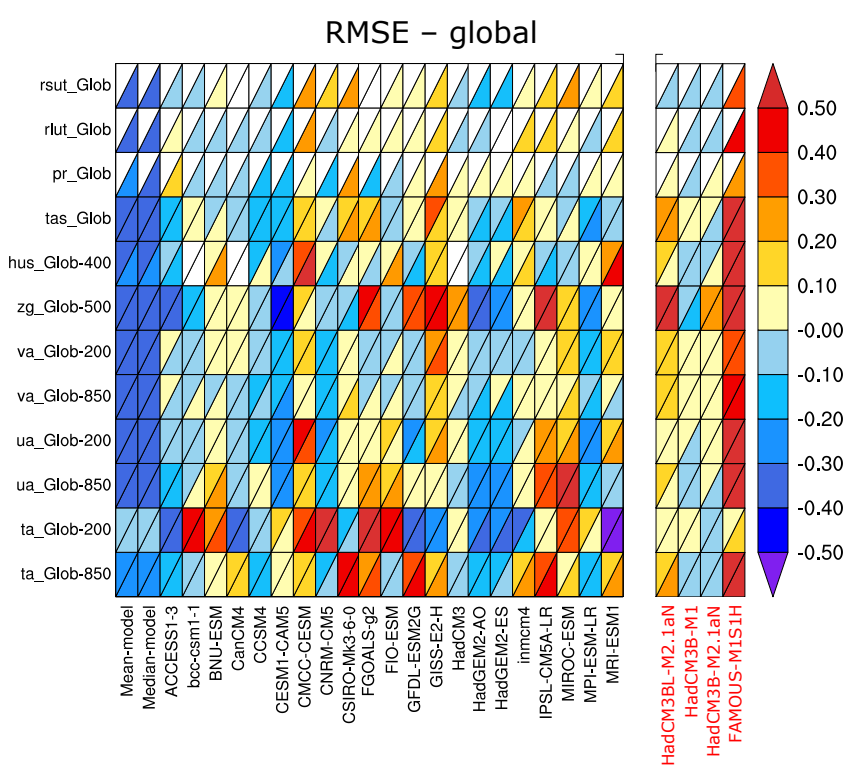

Figure 2. Relative error measure of the CMIP5 models (21 in total; in black) and the BRIDGE models (4 in total; in red) performance. Error measure is calculated from a time-space root-mean square error (RMSE) of contemporary and predecessor CMIP5 model historical climatological (1980-2005) seasonal cycle simulations and BRIDGE pre-industrial seasonal cycle climatologies against observations (1980-2005) for a set of nine different atmospheric variables. Error for each individual variable is characterised as a relative error by normalising the result of the median error of all model results (Gleckler et al., 2008); the BRIDGE models are not included in the mean/median error. For instance, a value of 0.20 indicates that a model's RMSE is $20 \%$ larger than the median CMIP5 error for that variable, whereas a value of -0.20 means the error is $20 \%$ smaller than the median error. The diagonal split grid square shows the relative error for the reference observed/reanalysis dataset (lower right triangle) and the alternative dataset (top left triangle). White triangles/boxes indicate where no data were available. Evaluated global atmospheric variables are TOA outgoing all-sky short-wave radiation (rsut_Glob), TOA outgoing all-sky outgoing long-wave radiation (rlut_Glob), precipitation (pr_Glob), near-surface temperature (tas_Glob), specific humidity at $400 \mathrm{hPa}$ (hus_Glob-400), geopotential at $500 \mathrm{hPa}$ (zg_Glob-500), V-wind at $200 \mathrm{hPa}$ (va_Glob-200), $\mathrm{V}$-wind at $850 \mathrm{hPa}$ (va_Glob-850), U-wind at $200 \mathrm{hPa}$ (ua_Glob200), U-wind at $850 \mathrm{hPa}$ (ua_Glob-850), temperature at $200 \mathrm{hPa}$ (ta_Glob-200), and temperature at $850 \mathrm{hPa}$ (ta_Glob-850).

and $200 \mathrm{hPa}$ ), U-wind (at 850 and $200 \mathrm{hPa}$ ), and $1.5 \mathrm{~m}$ surface temperature. It is likely that the course resolution of FAMOUS has a detrimental impact on its performance. The following sections provide a more detailed evaluation of various atmosphere, ocean, and land surface variables in the BRIDGE model suite. 
Table 4. Observational and reanalysis datasets used for the evaluation in Fig. 2.

\begin{tabular}{|c|c|c|c|}
\hline Performance metric & Obs. dataset & Re-analysis dataset & Year(s) for comparison \\
\hline $\begin{array}{l}\text { TOA outgoing all-sky short-wave radiation } \\
\text { (rsut_Glob) }\end{array}$ & CERES-EBAF & - & 2001-2012 \\
\hline $\begin{array}{l}\text { TOA outgoing all-sky long-wave radiation } \\
\text { (rlut_Glob) }\end{array}$ & CERES-EBAF & - & 2001-2012 \\
\hline $\begin{array}{l}\text { Precipitation } \\
\text { (pr_Glob) }\end{array}$ & GPCP-SG & - & 1979-2005 \\
\hline Near-surface temperature & - & ERA-Interim & 1979-2005 \\
\hline (tas_Glob) & & NCEP & 1979-2005 \\
\hline Specific humidity $(400 \mathrm{hPa})$ & - & ERA-Interim & 1979-2005 \\
\hline (hus_Glob-400) & AIRS & - & $2003-2010$ \\
\hline Geopotential height $(500 \mathrm{hPa})$ & - & ERA-Interim & 1979-2005 \\
\hline (zg_Glob-500) & & NCEP & 1979-2005 \\
\hline V-wind height $(200 \mathrm{hPa})$ & - & ERA-Interim & 1979-2005 \\
\hline (va_Glob-200) & & NCEP & 1979-2005 \\
\hline $\mathrm{V}$-wind height $(850 \mathrm{hPa})$ & - & ERA-Interim & 1979-2005 \\
\hline (va_Glob-850) & & NCEP & 1979-2005 \\
\hline U-wind height $(200 \mathrm{hPa})$ & - & ERA-Interim & 1979-2005 \\
\hline (ua_Glob-200) & & NCEP & 1979-2005 \\
\hline U-wind height $(850 \mathrm{hPa})$ & - & ERA-Interim & 1979-2005 \\
\hline (ua_Glob-850) & & NCEP & 1979-2005 \\
\hline Temperature $(200 \mathrm{hPa})$ & - & ERA-Interim & 1979-2005 \\
\hline (ta_Glob-200) & & NCEP & 1979-2005 \\
\hline Temperature $(850 \mathrm{hPa})$ & - & ERA-Interim & 1979-2005 \\
\hline (ta_Glob-850) & & NCEP & 1979-2005 \\
\hline
\end{tabular}

\subsection{Atmosphere}

\subsubsection{Surface temperature patterns}

We compare the modelled temperature and precipitation to observational data provided by the University of East Anglia high-resolution climatology for 1960-1990 (CRU CL v2.0) (New et al., 2002). This record is based on a range of weather stations totalling more than 10000 stations for temperature and more than 25000 stations for precipitation, with the best spatial coverage over North America, Europe, and India and the sparsest spatial coverage over the interiors of South America and Africa and Antarctica. Modelled SAT fields were masked to model land points only and differences to observations were done at the same resolution as the relevant model, as shown in Fig. 3.

It should be noted that the comparison between the versions of the HadCM3B family and the observed CRU CL v2.0 data is not a "clean" comparison. The observed data are for 1960-1990, whereas all model simulations are for the pre-industrial period. In the case of HadAMB3 simulations, the SSTs used are the 1870-1900 means of HadISST. To evaluate the impact of this effect, we examined the CMIP5 historical experiment of HadCM3-M1 done at the Hadley Centre (Smith et al., 2007, 2010). The differences between the 1960-1990 climate means compared to the 1860-1890 climate means were generally small compared to the model biases, with the overall mean warming between the two periods being $0.6^{\circ} \mathrm{C}$. Similarly, the four CMIP5 simulations are averages from 1860 to 1890 of the historical runs (using one ensemble member only, r1i1p1), and so the comparisons to the HadCM3B family are not perfectly clean.

HadCM3B-M1 (Fig. 3a) generally has a small cold bias compared to the data, with most regions experiencing colder temperatures by 2 to $3{ }^{\circ} \mathrm{C}$. The area-weighted RMSE is $2.8^{\circ} \mathrm{C}$, but with smaller errors in the tropics and a small warm bias in South America. There is also a small warm bias over Greenland, but this should be treated with some caution since there are issues about elevation effects and the data are relatively sparse in this region. The results for Fig. 3a are largely identical to those calculated using the CMIP5 HadCM3-M1 archived data (run by the UK Hadley Centre) for the historical run averaged between 1860 and 1899 inclusive (not shown). The differences are mostly less than $0.5^{\circ} \mathrm{C}$ and never exceed $1^{\circ} \mathrm{C}$, with a RMSE of $0.5^{\circ} \mathrm{C}$. Differences between the 1860-1889 average and the 19601989 average for the CMIP5 historical run are small, verifying that the model biases greatly exceed any differences between pre-industrial and modern temperatures. However, the small warming that does occur between 1860-1889 and 1960-1989 does reduce the cold bias marginally (RMSE decreased by $0.1^{\circ} \mathrm{C}$ )

Using MOSES2, HadCM3B-M2.1a (Fig. 3b) shows a significant reduction in the cold bias, resulting in a RMSE of 


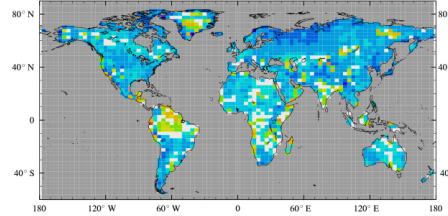

(a) HadCM3B-MI - Obs_UEA_21601080

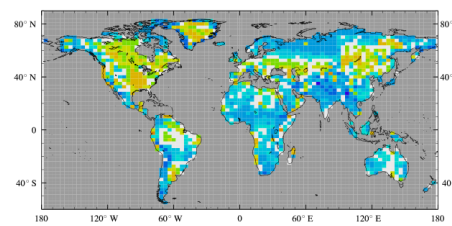

(e) HadAM3B-M2.1aN - Obs_UEA_21601080

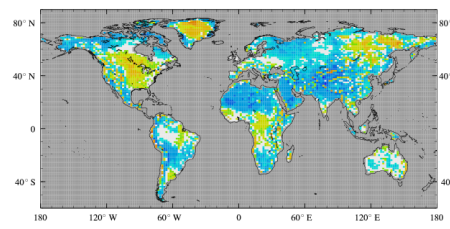

(i) ACCESS10_hist_r1 - Obs_UEA_21601080

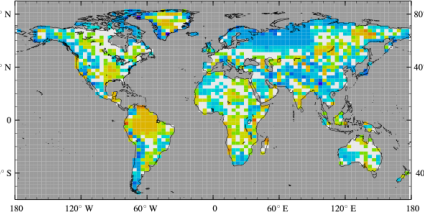

(b) HadCM3B-M2.1aN - Obs_UEA_21601080

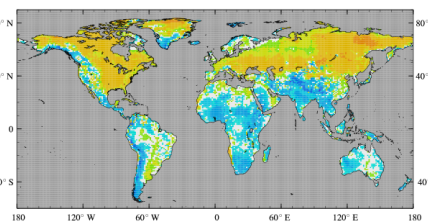

(f) HadAM3BH-M2.1aN - Obs_UEA_21601080

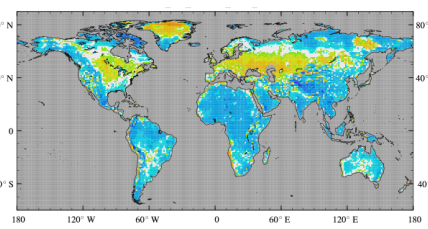

(j) CCSM4_hist_r1 - Obs_UEA_21601080

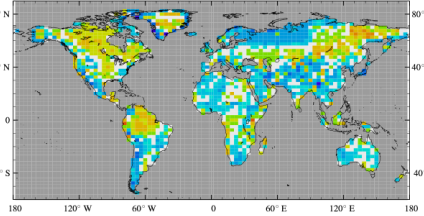

(c) HadCM3B-M2.2N - Obs_UEA_21601080

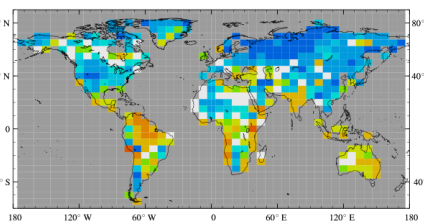

(g) FAMOUSMI - Obs_UEA_21601080

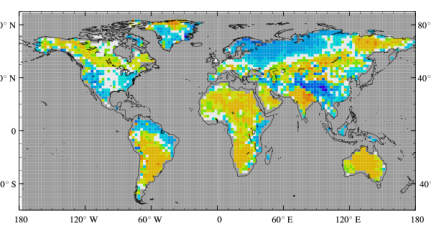

(k) GISSE2H_hist_r1 - Obs_UEA_21601080

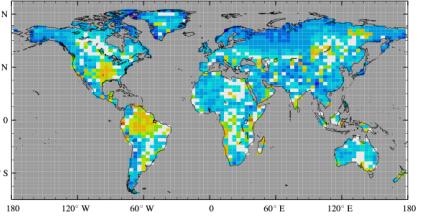

(d) HadCM3BL-M2.1aN - Obs_UEA_21601080

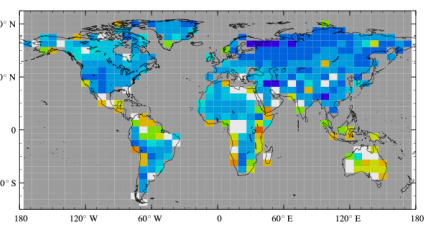

(h) FAMOUSM2.2N - Obs_UEA_21601080

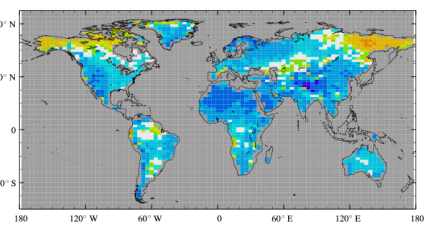

(1) IPSLCMSALR_hist_r1 - Obs_UEA_21601080

$-15 \quad-10$

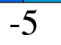

$-2$

$-1$

$\begin{array}{lll}1 & 2 & 5\end{array}$

10

15

Figure 3. (a) The difference between the annual mean surface air temperature (in ${ }^{\circ} \mathrm{C}$ ) of $\mathrm{HadCM} 3 \mathrm{~B}-\mathrm{M} 1$ and the $\mathrm{CRU} \mathrm{CL}$ v2.0 for the period 1960-1990 regridded onto the HadCM3B-M1 grid, (b) As (a) for the HadCM3B-M2.1a version, (c) As (a) but for HadCM3B-M2.2, (d) As (a) but for the HadCM3BL-M2.1aN version, (e) As (a) but for HadAM3B-M2.1a, (f) As (a) but for HadAM3BH-M2.1a, (g) As (a) but for FAMOUS-M1, and (h) As (a) but for FAMOUS-M2.2. Panels (i, j, k, l) show comparable results for four CMIP5 models, ACCESS1-0, CCSM4, GISS-E2-H and IPSL-CM5A-LR respectively. These were chosen to represent two models which were above the CMIP5 average in terms of their RMSE with respect to surface air temperature, and two models which were below average. All differences are calculated by regridding the CRU data onto the corresponding model grid, using simple bi-linear interpolation.

$2.1{ }^{\circ} \mathrm{C}$. The cold bias has reduced but still remains over northern Russia and Scandinavia, while over South America (Amazon) and Greenland the warm anomalies have intensified. Over the Amazon this is likely due to the difficulties in the vegetation model (see Sect. 5.3.1), while difficulties with Greenland were mentioned above. Elsewhere, the general cool bias seen in Fig. 3a has gone, replaced by anomalies of \pm 2 to $5^{\circ} \mathrm{C}$, with few widespread regional anomalies. Similarly, HadCM3B-M2.2N (Fig. 3c) also shows a reduced cold bias, with a RMSE of $2.1^{\circ} \mathrm{C}$. This model variant shows a slight reduction in the warm anomaly observed over the Amazon compared to Fig. 3b, but has a more extensive warm bias of 1 to $2^{\circ} \mathrm{C}$ at higher northern latitudes, e.g. over North America.

HadCM3BL-M2.1a (Fig. 3d) has a RMSE of $2.6^{\circ} \mathrm{C}$ and a comparable cold bias to HadCM3B-M1. As with the HadCM3B model variants, using MOSES2 with HadCM3BL reduces the cold bias and RMSE compared to using MOSES1, with HadCM3BL-M1 having a much higher RMSE (not shown). Once again, the high northern latitudes (particularly over Russia and Scandinavia) are too cold, which is the result of an exaggerated seasonal cycle due to an overly cold winter. This is also the case for other HadCM3B model variants, but it is most pronounced for the
HadCM3BL variants. Similarly to the other simulations using MOSES 2, the Amazon remains slightly warmer than the observations with slightly reduced broadleaf forest cover (see Sect. 5.3.1).

The atmosphere-only models vary significantly depending on their resolution. At standard resolution, HadAM3BM2.1a (Fig. 3e) shows similar spatial anomalies and RMSE to Fig. 3a-d, but greater warm biases over North America and Greenland of up to $5^{\circ} \mathrm{C}$ and cool biases over Africa and southern Asia of 2 to $5^{\circ} \mathrm{C}$. However, it has the smallest anomaly over the Amazon compared to the other standard resolution model variants, and a comparable $\operatorname{RMSE}\left(2.3^{\circ} \mathrm{C}\right)$. HadAM3BH-M2.1a (Fig. 3f) on the other hand shows a markedly different spatial pattern in its temperature biases to the model versions already described. It is the only simulation not to show a global cold bias. This is due to warmer than observed temperatures of 2 to $5^{\circ} \mathrm{C}$ over the majority of land surfaces north of $30^{\circ} \mathrm{N}$ (with the exception of the southern tip of Greenland and mountainous regions). It has a slight cold bias of 1 to $2^{\circ} \mathrm{C}$ over areas south of $30^{\circ} \mathrm{N}$ (with the exception of some regions in South America). Although these biases are extensive spatially, they are not of greater magnitude than the regional biases found in other model variants 
or CMIP5 models and the RMSE of the HadAM3BH-M2.1a simulation is $2.2^{\circ} \mathrm{C}$.

The FAMOUS model variants (Fig. $3 \mathrm{~g}$ and $\mathrm{h}$ ) have larger RMSE values than the higher-resolution model variants and the other CMIP5 models. FAMOUS-M2.2 (Fig. 3h) is the worse of the two, with a RMSE of $4.1^{\circ} \mathrm{C}$ and extreme cold biases over Northern Hemisphere continents, which exceed $10^{\circ} \mathrm{C}$ around Scandinavia. The cold bias in Fig. $3 \mathrm{~g}$ is less extreme, but instead has a warm bias in South America of up to 5 to $10^{\circ} \mathrm{C}$ and up to 2 to $5^{\circ} \mathrm{C}$ over India and Australia. There is some improvement in the RMSE for FAMOUS-M1, but it is still much higher $\left(3.3^{\circ} \mathrm{C}\right)$ than the higher-resolution model variants.

Some of the differences between the mean annual temperature biases in the models are due to changes in the models themselves. For instance, the improvements generally seen between models with MOSES1 and MOSES2.1 are primarily due to the better representation of the land surface, particularly the snow cover, as discussed above. It is also notable that the lower-resolution ocean models tend to be cooler at the higher latitudes, as the lower-resolution ocean makes it more difficult to move heat away from the Equator.

For comparison, we show the SAT fields from four CMIP5 models (Fig. 3i-1), selected based on the results of the IPCC AR5 WG1 model evaluation (Sect. 9). We selected two models which were above average for their simulation of SAT (ACCESS1-0 and CCSM4) and two models which were below average (GISS-E2-H and IPSL-CM5A-LR). In all cases these models are not the best or worst extremes, but represent the typical range of model skill. Again, the observations have been interpolated onto the appropriate resolution of the model from which the RMSE was calculated. As can be seen, the general picture that emerges is that most of the varieties of HadCM3B (except perhaps for FAMOUS) are well within the skill of the CMIP5 ensemble. The CMIP5 models all show large regional biases of up to $\pm 5^{\circ} \mathrm{C}$ (with little consistency on the sign of the anomaly between them) and the RMSE scores range from 2.3 to $3.3^{\circ} \mathrm{C}$, which are similar to the varieties of the HadCM3B model. Indeed HadCM3BM2.1aN and HadCM3B-M2.2 have the smallest RMSE values of the models sampled.

\subsubsection{Precipitation}

Figure 2 shows that the BRIDGE models with the exception of FAMOUS produce annual precipitation amounts comparable to other CMIP5 models, suggesting that our models are capturing the general synoptic-scale features (frontal, convective and mesoscale).

While global annual RMSEs for the BRIDGE models compare favourably, it is also key to investigate the mean spatial patterns of precipitation to ascertain whether the models are reproducing these patterns in accordance with the observations. We assess annual climatological precipitation for the BRIDGE model suite against CRU CL v2.0 (New et al., 2002), a high-resolution $\left(0.5^{\circ} \times 0.5^{\circ}\right)$ global land surface product (excluding Antarctica). The resolution is transformed (bi-linear interpolation) to the appropriate grid in the model. We are again comparing our pre-industrial simulations with 1960-1990 observations, but the model biases are generally much larger than any trends.

Figure 4 shows the regional biases in mean annual precipitation, expressed as a \% error compared to the CRU CL data. For consistency with the previous figure, we also include the same four CMIP5 models. Regionally, spatial patterns in precipitation bias are generally consistent between the different BRIDGE models and broadly comparable to their CMIP5 models.

The BRIDGE simulations have a similar problem to many CMIP5 models in that they overestimate precipitation in regions of topography. This is particularly noticeable around the Himalayas and Tibet, but is also visible on the upstream side of the Rockies and Andes. This may be due to poor representation of moisture gradients and regional dynamics. However, the apparent discrepancy with observations can be amplified by a known negative bias in gauge stations (Adam et al., 2006). Gauge stations also underestimate precipitation leeward of mountain ranges (e.g. Himalayas and Andes), as well as over arid regions, which can contribute to model-data discrepancy in these regions also.

Monsoonal regions of South-east Asia, Australasia, southern South America, and western and central Africa overestimate precipitation by 0.5 to $2 \mathrm{~mm} \mathrm{day}^{-1}$ but underestimate precipitation in the Indian and northern arm of the South American region by $\sim 1$ to $4 \mathrm{~mm} \mathrm{day}^{-1}$. There are however some exceptions with HadAM3B-M2.1a (Fig. 4), an atmosphere-only GCM using observed SST (HadISST 18701900) producing a more reasonable precipitation signal compared to the observations, suggesting the importance in the accuracy of SST/local ocean circulation dependency (this is also seen in Australia). There is still a problem with the ITCZ location over South America being too far south, giving this north-south dipole in negative/positive anomalies.

It is also noted that an increase in resolution does not produce a noticeable improvement in spatial annual precipitation bias in certain monsoon regions in the BRIDGE models (Fig. 4f compared to Fig. 4j), again suggesting the importance of accuracy in SST and ocean circulation, with the exception of South America, where there is improvement. Spatially, increased resolution does not affect the sign of anomaly or the spatial patterns of precipitation regionally (with the exception of South America) throughout the BRIDGE suite of models; however, the magnitude of the precipitation bias does progressively decrease.

\subsubsection{Horizontal heat transports}

There is broad agreement between the observed and simulated total northward heat transport. Similarly, the partitioning between the ocean and the atmosphere is qualitatively 


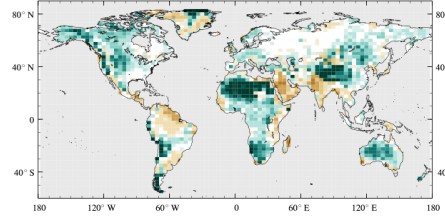

(a) HadCM3B-M1 - Obs_UEA_21601080

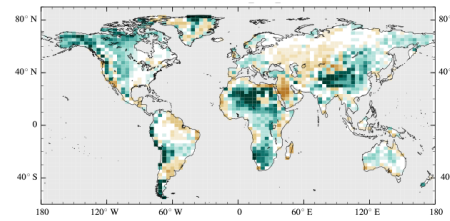

(e) HadAM3B-M2.1aN - Obs_UEA_21601080

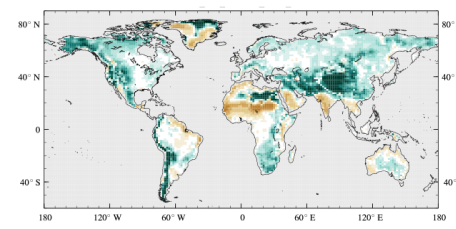

(i) ACCESS10_hist_r1 - Obs_UEA_21601080

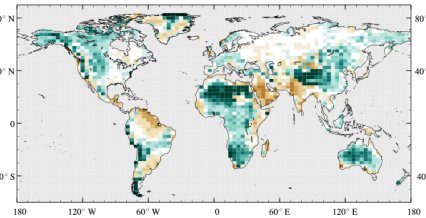

(b) HadCM3B-M2.1aN - Obs_UEA_21601080

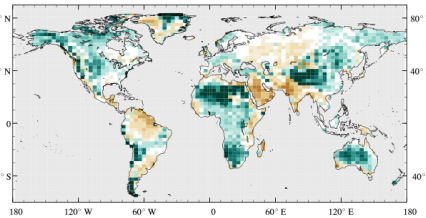

(c) HadCM3B-M2.2N - Obs_UEA_21601080

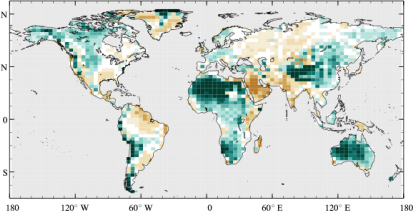

(d) HadCM3BL-M2.1aN - Obs_UEA_21601080

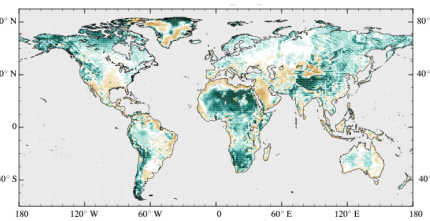

(f) HadAM3BH-M2.1aN - Obs_UEA_21601080

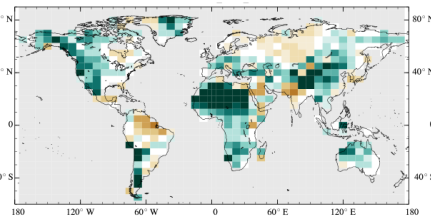

(g) FAMOUSM1 - Obs_UEA_21601080

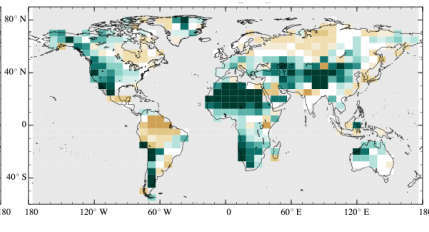

(h) FAMOUSM2.2N - Obs_UEA_21601080

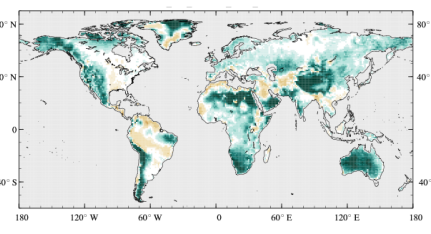

(j) CCSM4_hist_r1 - Obs_UEA_21601080

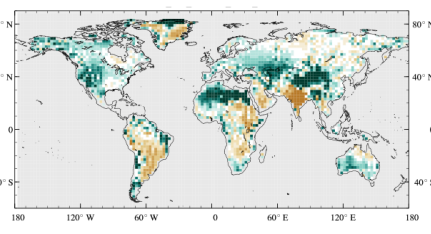

(k) GISSE2H_hist_r1 - Obs_UEA_21601080

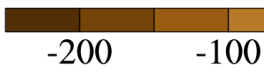

$-20$

10

40

80

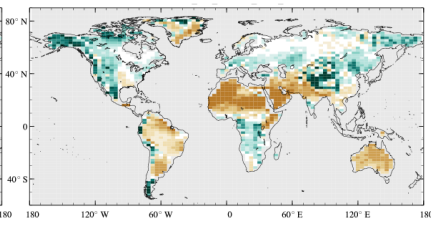

(1) IPSLCM5ALR_hist_r1 - Obs_UEA_21601080

Figure 4. As for Fig. 3 but showing the difference in mean annual precipitation, expressed as a \% difference to the CRU CL v2.0 observations.

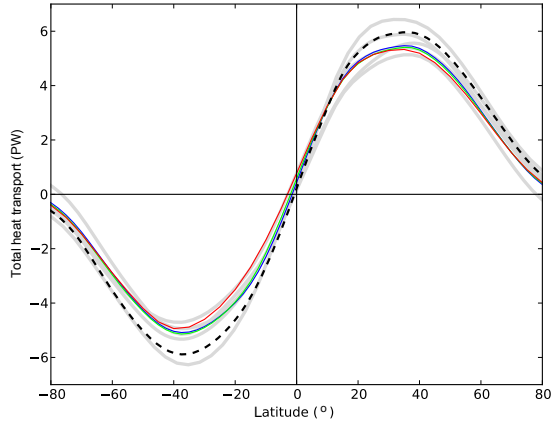

(a) Total

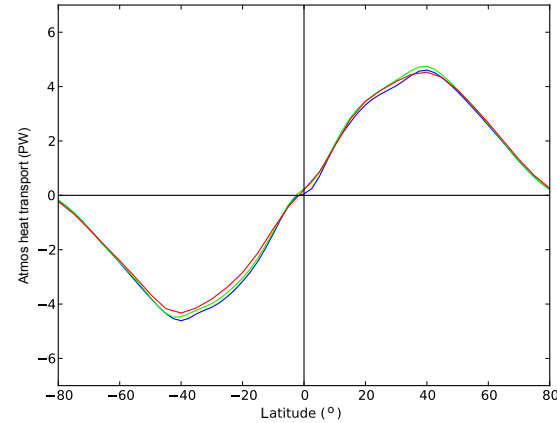

(b) Atmosphere

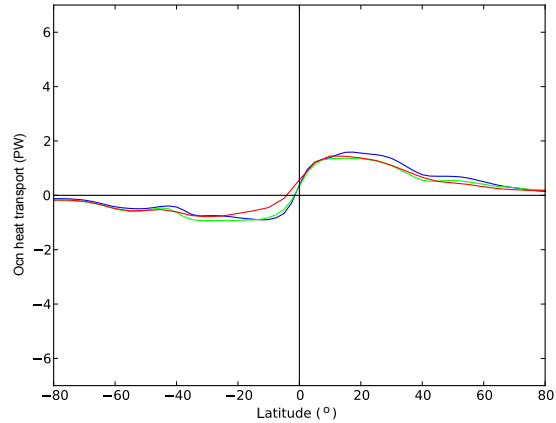

(c) Ocean

Figure 5. The annual mean northward heat transport in total, the atmosphere, and the ocean. The black line shows the observational estimate, blue HadCM3B-M2.1a, green HadCM3BL-M2.1a, and red FAMOUS-M2.2; grey lines show transports for a selection of CMIP5 models. These transports are calculated as the implied heat transports from the TOA and surface energy fluxes (see Trenberth and Fasullo, 2013, for details). Observational estimates for the total transport are derived from the CERES data.

similar to that estimated by Trenberth and Fasullo (2013). We find that all versions of the model simulate heat transport and are consistent with CMIP5 models (see the grey lines in Fig. 5). However, in common with almost all other climate models, we find that on the Equator, although the total heat transport is northward, in agreement with the observations, the atmospheric heat transport is also northward, contrary to the observed southward transport (Loeb et al., 2016). The cause of this in any of the models in which it is a feature is unclear. The three versions of HadCM3B show remarkably similar amounts of total heat transport; the major difference is FAMOUS, which underestimates the southward heat transport in the Southern Hemisphere subtropics rather more than HadCM3B and HadCM3BL. This is due to the smaller amount of ocean heat transport in this region in FAMOUS. This discrepancy is not due to the coarse resolution of the FAMOUS ocean because, interestingly, in this region the ocean heat transport in HadCM3BL is very similar to HadCM3B, whose ocean resolution is quite different. Therefore it is more likely that the difference arises from the atmospheric forcing of the surface ocean. In the Northern Hemisphere the HadCM3BL ocean heat transport is more similar to FAMOUS, suggesting that the ocean resolution is more important here. This is likely due to the processes that de- 
termine the ocean's overturning circulation being simulated rather differently in the higher- and lower-resolution models.

\subsection{Ocean}

\subsubsection{Sea surface temperature}

The BRIDGE suite of models is capable of reproducing the broad global latitudinal patterns and gradients in SST (Fig. 6). Nonetheless, some cold and warm biases of over $8^{\circ} \mathrm{C}$ are present, especially where sharp fronts and boundary currents are not resolved. Other biases of similar magnitude also appear in the upwelling regions (e.g. west of Africa and of South America), and again these are likely associated with processes that are not fully resolved by the model. Colder SSTs in the sub-polar North Atlantic for all models are not uncommon and likely due to the coarse resolution (e.g. Marzocchi et al., 2015a). This can be seen by comparing HadCM3B and HadCM3BL, which are models that differ most in their ocean resolution. Cold biases in the Northern Hemisphere are more extensive in HadCM3BL than in HadCM3B. Warmer SSTs of up to $8{ }^{\circ} \mathrm{C}$ are present in the Southern Hemisphere, especially in the Southern Ocean, in both HadCM3B and HadCM3BL. FAMOUS is characterised by colder than observed SSTs in the Northern Hemisphere, in common with HadCM3B and HadCM3BL, and warmer SSTs by up to $8^{\circ} \mathrm{C}$ almost everywhere in the Southern Hemisphere despite the bias in ocean heat transport. HadCM3B and HadCM3BL do not show any notably larger biases when compared to typical CMIP5 models. All of the HadCM3B models, including FAMOUS, show smaller temperature biases in the Southern Ocean than GISS-E2-H, and the biases in the North Pacific are of a similar magnitude to those in IPSL-CM5A-LR.

\subsubsection{Sea surface salinity}

The broad global latitudinal patterns of sea surface salinity are realistically reproduced by the suite of BRIDGE simulations (Fig. 7). However, on the global average, the models show a fresh bias of about $0.5 \mathrm{~g} \mathrm{~kg}^{-1}$; as we shall show in the following section, this is likely related to the rather different vertical structure of the ocean in the model than in the observations. In all models, substantial differences from the observations are found in the Arctic Ocean, exhibiting higher salinities (up to $10 \mathrm{~g} \mathrm{~kg}^{-1}$ ) in the Kara Sea and generally north of Russia. Generally lower salinities (of up to $5 \mathrm{~g} \mathrm{~kg}^{-1}$ ) are found in the Chukchi and Beaufort seas. The largest differences are found in enclosed or semi-enclosed basins, such as the Mediterranean Sea, where it is more saline, or the Black Sea, Caspian Sea, and Hudson Bay, where it is markedly fresher. In all versions of the model the subtropical North Atlantic tends to be more saline than the observations.

Substantial differences from the observations can also be found in CMIP5 models (Fig. 7g-h), with magnitudes com- parable to the BRIDGE models. We note that some of the differences at high latitudes could be due to biases in the simulation of sea ice concentration and distribution.

\subsubsection{The Atlantic Meridional Overturning Circulation}

Figure 8 shows the mean strength of the Atlantic Meridional Overturning Circulation (AMOC) for the three main model families (HadCM3B, HadCM3BL, and FAMOUS). Values are shown as zonally integrated depth profiles measured in terms of the northward flow of water at $26.25^{\circ} \mathrm{N}$. The modelled AMOC is compared to observations from the Rapid Climate Change-Meridional Overturning Circulation and Heatflux Array (RAPID-MOCHA) at $26.5^{\circ} \mathrm{N}$ (Smeed et al., 2015), which have been calculated from daily data spanning 2 April 2004 to 30 March 2015.

The strength of the AMOC varies on an annual basis, so a range of values is shown for both the models and observations, with the depth at which the AMOC peaks highlighted with a point. The peak flow of the North Atlantic Deep Water (NADW) cell identified by the RAPID-MOCHA array lies at around $1000 \mathrm{~m}$ and varies from year to year between 14 and 19Sv. All three models do a reasonable job of modelling the NADW cell in terms of the magnitude of maximum flow. However, maximum overturning is too shallow for all model variants, peaking at approximately $800 \mathrm{~m}$. HadCM3BL shows larger year to year variability than the observations: approximately twice as large as that in the observations. This results in years with a lower minimum volume transport than are seen in the observations. FAMOUS model variants tend to underestimate the year to year variation by approximately $50 \%$, although this is in contrast to the study of Sarojini et al. (2011), who showed that FAMOUS exhibited greater short-term variability than the RAPID-MOCHA array. HadCM3B variants have a realistic year to year variability, at least in the upper $1500 \mathrm{~m}$ of the ocean.

All of the models do a poor job at representing the flow of the NADW cell below $2000 \mathrm{~m}$ depth. McCarthy et al. (2012) showed that at this latitude, approximately $60 \%$ of the southward return flow is comprised of upper NADW (between 1100 and $3000 \mathrm{~m}$ ) and $40 \%$ of the lower NADW (between 3000 and $5000 \mathrm{~m}$ ). The modelled stream functions show that the return flow is shifted to shallower depths, indicating a shallower overturning in all of the model variants.

The CMIP5 models exhibit a wide spread in the mean strength of the AMOC, ranging from 13 to $31 \mathrm{~Sv}$ and peaking at latitudes between 20 and $60^{\circ} \mathrm{N}$ (e.g. Zhang and Wang, 2013). It was not possible to include the CMIP5 models in Fig. 8; however, the studies of Roberts et al. (2013) and Msadek et al. (2013) produced similar plots of AMOC zonally integrated depth profiles for a range of models compared to observations (their Figs. 1 and 3 respectively). The HadCM3B and FAMOUS variants are shown to have very similar streamfunction profiles to GFDL Climate Model 2.1, NCAR CCSM4 models, and the MPI models, and more accu- 


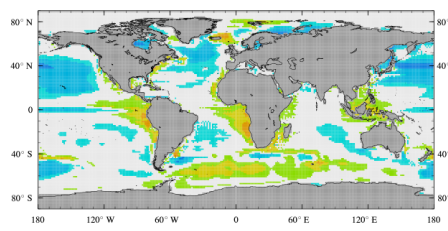

(a) HadCM3B-M1 - Levitus

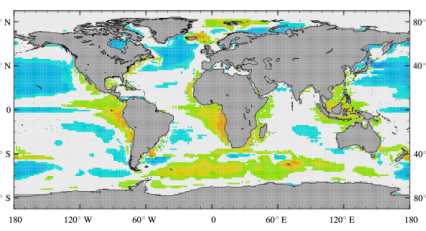

(b) HadCM3B-M2.1 aN - Levitus

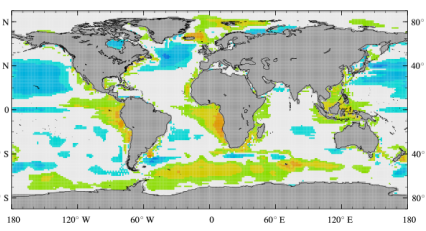

(c) HadCM3B-M2.2N - Levitus

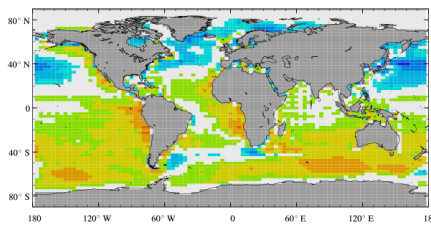

(e) FAMOUSM1 - Levitus

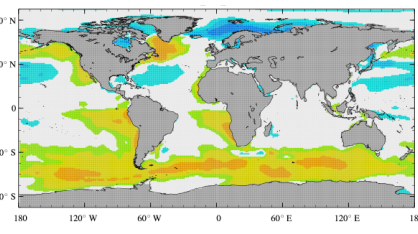

(i) GISSE2H_hist_r1 - Levitus

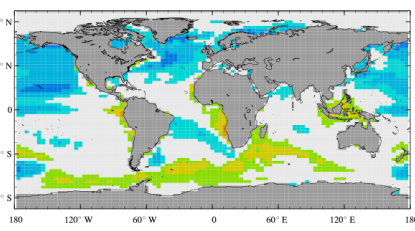

(d) HadCM3BL-M2.1aN - Levitus

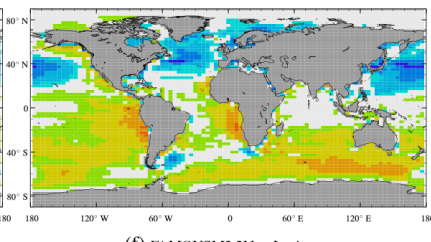

(f) FAMOUSM2.2N - Levitus

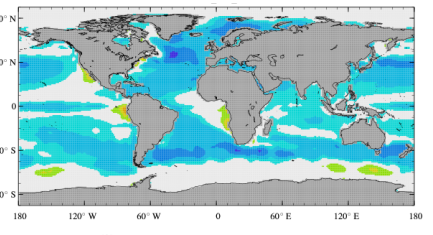

(j) IPSLCM5ALR_hist_r1 - Levitus

\section{$\begin{array}{llllllllll}-16 & -8 & -4 & -2 & -1 & 1 & 2 & 4 & 8 & 16\end{array}$}

Figure 6. Annual mean sea surface temperature differences (in ${ }^{\circ} \mathrm{C}$ ) for a range of coupled model simulations, and also for the same four CMIP5 models used in Figs. 3 and 4. The observational dataset is the Levitus World Ocean Atlas (2009) (Locarnini et al., 2010). The figure shows the difference in SST between model and observations for (a) HadCM3B-M1, (b) HadCM3B-M2.1a, (c) HadCM3B-M2.2, (d) HadCM3BL-M2.1a, (e) FAMOUS-M1, (f) FAMOUS-M2.2, (g) ACCESS1.0, (h) CCSM4, (i) GISS-E2-H, and (j) IPSL-CM5A-LR. Model output is regridded to the same resolution of the observations.

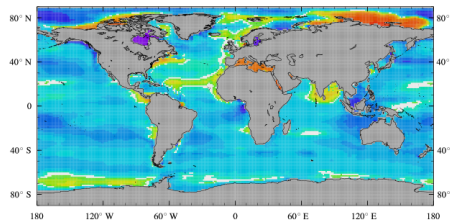

(a) HadCM3B-M1 - Levitus

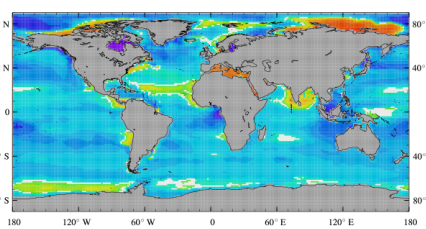

(b) HadCM3B-M2.1aN - Levitus

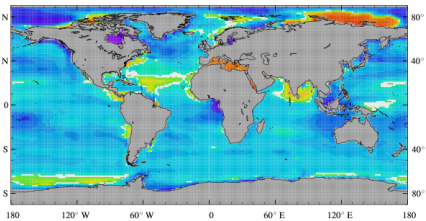

(c) HadCM3B-M2.2N - Levitus

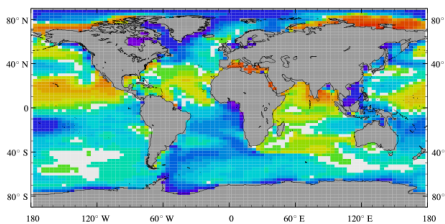

(e) FAMOUSM1 - Levitus

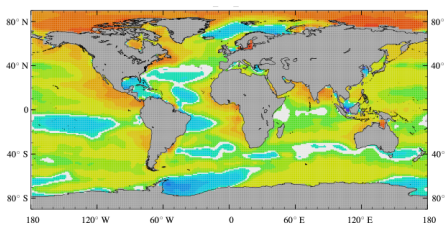

(g) GISSE2H_hist_rl - Levitus

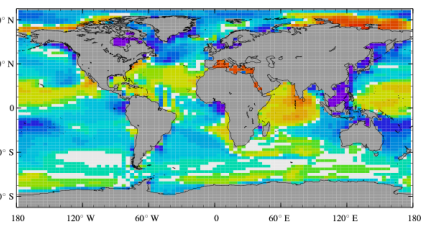

(d) HadCM3BL-M2.1aN - Levitus

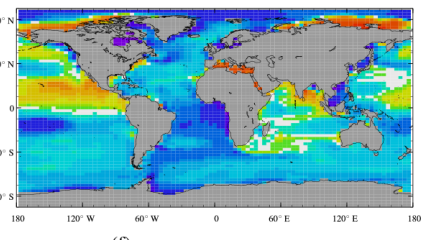

(f) FAMOUSM2.2N - Levitu

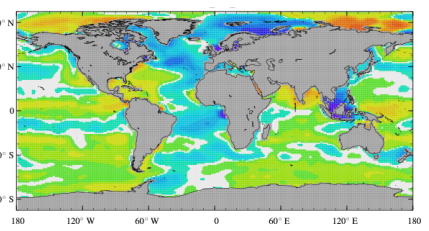

(h) IPSLCM5ALR_hist_rl - Levitus

\section{$\begin{array}{lllllllllllllllllllll}-10 & -5 & -3 & -2 & -1.5 & -1 & -0.5 & -0.3 & -0.1 & 0.1 & 0.3 & 0.5 & 1 & 1.5 & 2 & 3 & 5 & 10\end{array}$}

Figure 7. As Fig. 6 but showing the differences in sea surface salinity (in $\mathrm{g} \mathrm{kg}^{-1}$ ) between models and observations. (a) HadCM3B-M1, (b) HadCM3B-M2.1a, (c) HadCM3B-M2.2, (d) HadCM3BL-M2.1a, (e) FAMOUS-M1, (f) FAMOUS-M2.2, (g) GISS-E2-H, and (h) IPSLCM5A-LR. The observational dataset is the Levitus World Ocean Atlas (2009) (Antonov et al., 2010). Model output is regridded to the same resolution of the observations. 

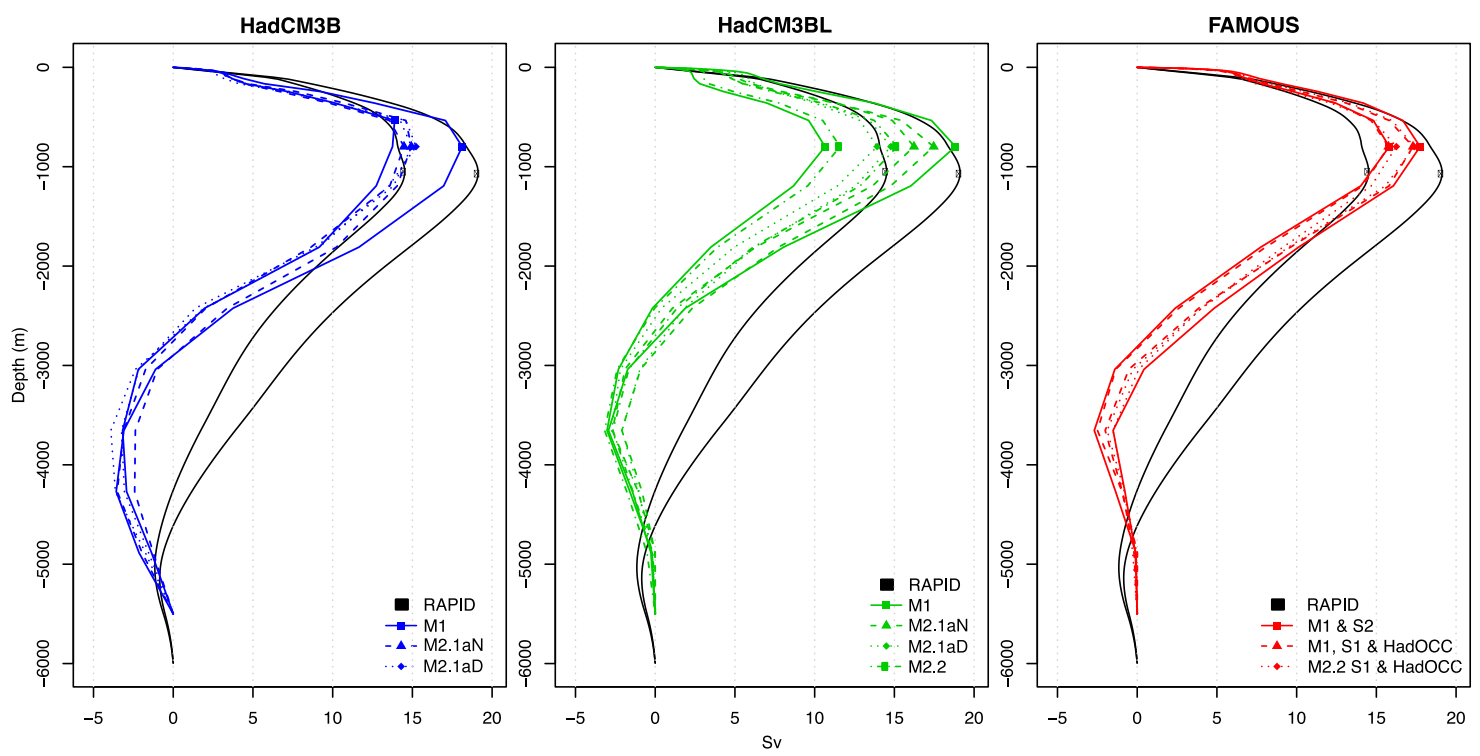

Figure 8. Annual depth profiles of the Atlantic Meridional Overturning Circulation (AMOC) at $26.25^{\circ} \mathrm{N}$ showing the range of values for variants of HadCM3B, HadCM3BL, and FAMOUS. Annual data from the RAPID array at $26.5^{\circ} \mathrm{N}$ are highlighted in grey. The depth at which the AMOC reaches its maximum is indicated with a point.

rately simulate the maximum overturning than the NorESM1 model variants. A similar pattern of biases is apparent in the vertical structure for these models, i.e. a too shallow overturning cell; however, the point of maximum overturning is shallower in the HadCM3B and FAMOUS variants.

This bias in the vertical structure has been attributed in some studies to inaccurate transport in the Nordic Sea overflows, which in the case of HadCM3B includes a greater than observed overflow across the Denmark Strait, in addition to sub-grid-scale processes (see Legg et al., 2009; Roberts et al., 2013). An additional cause of the shallow overturning may be the excessive surface salinity in the North Atlantic in all model versions, particularly around the subtropics as shown in Fig. 7. The study of Pardaens et al. (2003) investigated the freshwater budget in HadCM3B, concluding that in the North Atlantic saline conditions are primarily a result of excessive evaporation. Other components, such as insufficient subtropical runoff from the western coast, may also have an influence. This results in the Atlantic being too stratified and consequently too stable, which may reduce the depth of overturning.

A further consequence of this is a net northward transport of freshwater into the Atlantic (Liu et al., 2014), which may result in a monostable stability regime of the AMOC in HadCM3B instead of a bistable regime (Weaver et al., 2012; Liu et al., 2014). In contrast, Hawkins et al. (2011) have demonstrated a bistable regime in FAMOUS. Approximately $60 \%$ of the CMIP5 models have been shown to exhibit monostability (Weaver et al., 2012). However, this is contrary to what is indicated in the palaeorecord and inferred from the measurements of diagnostic indicators in the present-day ocean - that there is a net export of freshwater from the Atlantic and consequently that the AMOC may be in a bistable regime. This indicates that the AMOC may be artificially stable in the HadCM3B and FAMOUS model variants in addition to a range of other CMIP5 models. There remains uncertainty about this hypothesis however, with Sijp (2012) concluding that freshwater export may not be a reliable indicator of AMOC stability.

\subsection{Land}

\subsubsection{Vegetation distribution}

These models have a simple representation of terrestrial vegetation, with five plant functional types that each covers a large climatic range. Comparing the dominant PFT in the model to a reconstruction of pre-industrial vegetation ( $\mathrm{Ra}$ mankutty and Foley, 1999), we can see the model captures the overall correct pattern (Fig. 9), with slight errors of extent and/or exact location. Previous studies (Betts et al., 2004) which compared TRIFFID PFT distributions to the IGBPDIS land cover dataset (which represents the modern distribution of vegetation as derived from satellite image interpretation, Loveland and Belward (1997) found much of the same patterns.

The broadleaf trees in the tropics tend to extend too far, especially in the Southern Hemisphere, as can be seen in Fig. 9b-d. The southern mid-latitudes are difficult to capture accurately, for a variety of reasons, including the challenge of precipitation patterns in this region. The HadCM3BL model is significantly worse than either HadCM3B or HadAM3B in this regard. This is because of its decreased ocean resolution, 


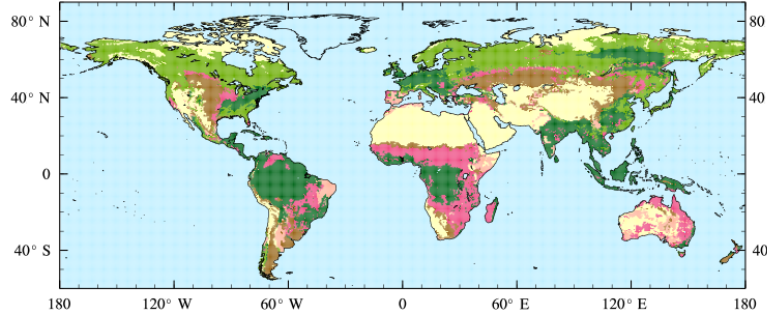

(a) R\&F 1999 data

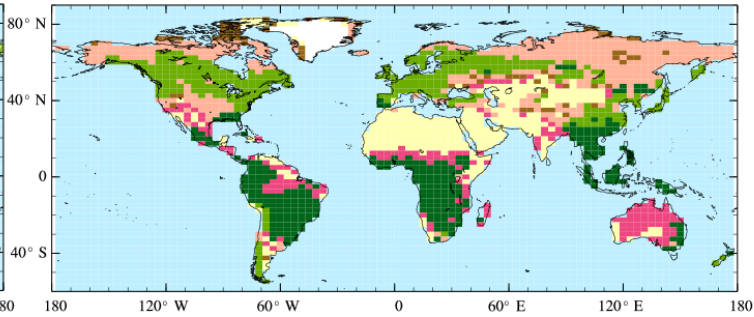

(b) HadCM3B-M2.1aD

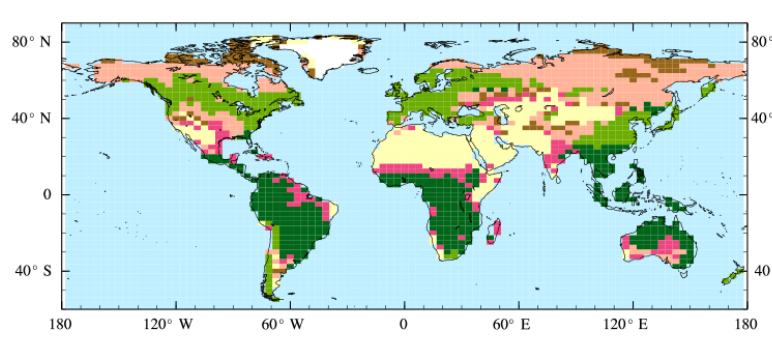

(c) HadCM3BL-M2.1aD

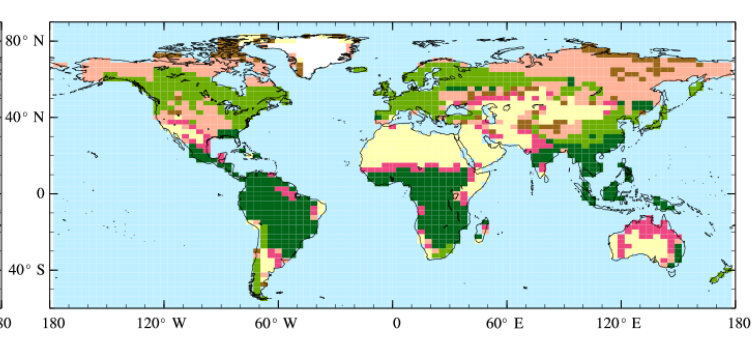

(d) HadAM3B-M2.1aD

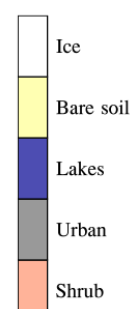

4 groundcover C3 groundcover Needleleaf trees Broadleaf trees Water

Figure 9. Maps of the dominant plant functional type for observations (a) and model simulations of the pre-industrial. The models shown are (b) HadCM3B-M2.1aD (c) HadCM3BL-M2.1aD and (d) HadAM3B-M2.1aD. The observed dataset for comparison is Ramankutty and Foley (1999).

which affects the sea surface temperature and therefore the water transport to the Amazon region.

A feature which appears in the HadCM3 and HadCM3 models is a tendency for the Amazon broadleaf forest extent to be underestimated at the mouth of the River Amazon, even at relatively low carbon dioxide concentrations (Fig. 9b-d compared to Fig. 9a). At higher carbon dioxide levels, this is a known feature of the model (Malhi et al., 2009; Betts et al., 2004) caused by ocean circulation resulting in insufficient precipitation to sustain the forest. The tendency of the coupled models to underestimate precipitation in this area is apparent in Fig. 4 and is particularly notable in HadCM3. This leads to TRIFFID modelling the presence of $\mathrm{C} 4$ grasses instead of broadleaf trees.

Grasses tend to be globally slightly underestimated with the position of vegetation in the Sahara and other arid regions well reproduced, but the density is modelled to be too sparse, particularly in south-western Africa, central and south-western Asia, south-western North America, and Australia.

The shrub PFT is overestimated at high latitudes, perhaps as a result of the high-latitude cold bias in the model. We can see this in these simulations (Fig. 9b-d compared to observations in Fig. 9a). The models simulate fewer needleleaf trees than observations for Ramankutty and Foley (1999), instead simulating shrubs. The models also underestimate the amount of grasses and bare soil.

The observational dataset is re-gridded from the original to the nine surface types in our models, which introduces more uncertainty. In particular, the dominant PFT obviously is a difficult metric to consider precisely, as it does not represent mixed vegetation systems such as Savannah, well. Some difficulties mainly originate in how areas such as tundra are allocated - to bare soil or to $\mathrm{C} 3$ grasses. Because of the limited number of PFTs in the model, C3 grass represents a large range of low-lying vegetation types, arguably also encompassing mosses and lichen and very sparse tundra vegetation.

There are also some uncertainties associated with the Ramankutty and Foley (1999) dataset, which is a reconstruction of pre-industrial vegetation. Other model-observation discrepancies have been suggested to be a combination of orographic representation leading to underestimation of precipitation and the inadequate treatment of natural disturbance mechanisms such as fire (Betts et al., 2004).

Though not shown, the equilibrium (run for 50 years every 5 years) simulations are very similar to the dynamic (run ever 10 days) ones, especially in the tree PFTs. That the equilibrium and dynamic simulations from the same model are very closely related suggests that although the inter-annual variability does have some influence on the vegetation, in general the mean climate is more important.

\subsubsection{Net primary productivity}

The NPP of the models, compared to MODIS 2001 NPP observations, is good at capturing the global latitudinal patterns, with higher NPP in the tropics and lower in other regions (see Fig. 10). One notable exception is the failure of the model to capture sub-tropical spikes in productivity, especially at around $20^{\circ} \mathrm{N}$, which is also underestimated in the CMIP5 models analysed here (shown by grey lines). The HadCM3B 


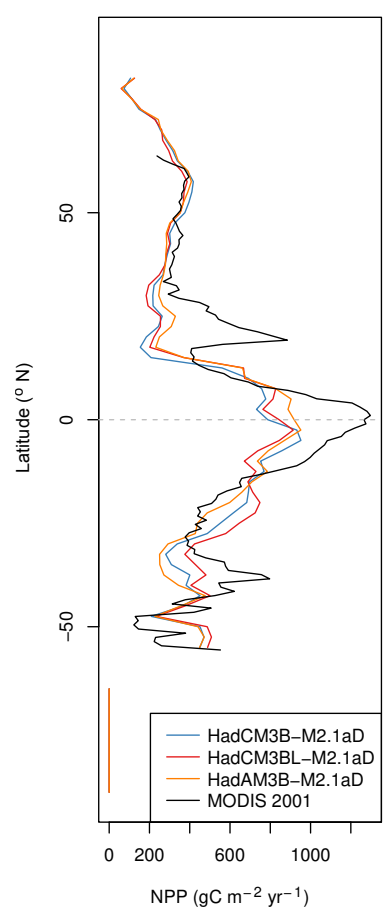

Figure 10. The latitudinal average NPP in $\mathrm{gCm}^{-2} \mathrm{yr}^{-1}$. CMIP5 models without dynamic vegetation plotted here are CCSM4 and IPSL-CM5A-LR. CMIP5 models with dynamic vegetation plotted here are MIROC-ESM and MPI-ESM.

productivity peak over the Amazon tropical area is lower in the model than observations. Overall, the NPP performance of our models compares favourably with that of CMIP5 models. The large range of NPP values of these CMIP5 models encompasses our models at nearly all latitudes.

The Amazon forest extends a little too far south in all the models, but this is a key area of difference as well, with HadAM3B models better capturing the observed distribution, and the lower-resolution ocean of HadCM3BL suffering the most from excess tropical forest. However, HadCM3BL models do better in the Southern Hemisphere, and better than HadCM3B in other parts of the tropics. As in the case of the PFT distribution (upon which the NPP is based), there is a close relationship between the equilibrium (not shown) and dynamic simulations of NPP.

\section{Summary and future directions}

This paper provides an overview of a variety of versions of the HadCM3 family of coupled climate models used in BRIDGE at the University of Bristol. In this study we have termed the BRIDGE variants HadCM3B, in order to distinguish our versions from those originally developed at the Met Office. We provide updated documentation of these variants, including atmosphere-only, low-resolution ocean, and highresolution atmosphere-only models, and including three al- ternative versions of the MOSES land surface scheme. Using an up-to-date set of observational benchmarks we show through detailed comparisons, that the models provide a good representation of large-scale features of the climate system, both over land and for the ocean. We additionally show that they remain comparable to most CMIP5 models.

The speed and relative complexity of HadCM3B and its variants creates opportunities for tackling a range of problems. Large ensembles are possible because of the relatively small number of processors required. Ensembles can explore probabilistic approaches to climate change quantification, model parametric uncertainty, or boundary condition uncertainty. Long integrations of many millennia are also possible, so that longer-term climate changes, for example covering the last deglaciation, can be investigated.

Several versions of the model are under continued development and improvement. For example, FAMOUS has been coupled to an interactive ice-sheet model (Gregory et al., 2012) to allow predictions of sea level and land ice on longer timescales. Further developments in this approach will allow more detailed investigation of climate-sea-level interactions for a variety of times in the past (e.g. Roberts et al., 2014). FAMOUS now also includes a marine carbon cycle (HadOCC) (Williams et al., 2013) and an oceanic oxygen cycle (Williams et al., 2014), allowing direct comparisons to biogeochemical cycles.

Currently a very high-resolution version of HadAM3BH is finalising development in Bristol. This uses a resolution of $0.625^{\circ} \times 0.4166^{\circ}(576 \times 433$ grid points, $\mathrm{N} 288)$ as this has been suggested as a minimum resolution for realistic simulation of the hydrological cycle (Demory et al., 2014). The model appears to be significantly computationally more efficient (approximately $10 \times$ faster) than a similar-resolution version of the more recent UK Met Office HadGEM3 model (Walters et al., 2014), because of the lower model top, simplified aerosol physics, and major differences in the underlying atmospheric dynamical core.

This paper motivates the continued development and scientific application of the HadCM3B family of coupled climate models. Future updates will cover new developments to the presented model version, bug corrections and enhancements.

Code availability. The UK Met Office made available the source code of HadCM3 via the Ported Unified Model release (http:// www.metoffice.gov.uk/research/collaboration/um-partnership). Enquiries regarding the use of HadCM3 should be directed in the first instance to the UM Partnership team, who can be contacted at um_collaboration@metoffice.gov.uk.

The main repository for the Met Office Unified Model (UM) version corresponding to the model presented here can be viewed at http://cms.ncas.ac.uk/code_browsers/UM4.5/UMbrowser/index. html.

The code detailing the advances described in this paper is completely contained within the files available as a Supplement to this 
paper. These files are known as code modification files or "mod" files and should be applied to the original code of the model. This is protected under UK Crown Copyright, as is the base code linked above.

The UM basis files for the simulations described in this paper can be found on the puma.nerc.ac.uk facility (please contact Andy Heaps for access: andy.heaps@ncas.ac.uk). The simulation names are the following.

- tcsyf: HadCM3B-M1

- tcywd: HadCM3B-M2.1aN

- tcyxc: HadCM3B-M2.2N

- tdbad: HadCM3BL-M2.1aN

- tdekd: HadAM3B-M2.1aN

- tdewb: HadAM3BH-M2.1aN

- tdexb: FAMOUS-M1

- tdeyb: FAMOUS-M2.2N

- tdkym: HadCM3B-M2.1aD

- tdkyn: HadCM3BL-M2.1aD

- tdkyo: HadAM3B-M2.1aD

Data availability. - The CERES data were obtained from the NASA Langley Research Center CERES ordering tool at http: //ceres.larc.nasa.gov/.

- We acknowledge the World Climate Research Programme's Working Group on Coupled Modelling, which is responsible for CMIP, and we thank the climate modelling groups for producing and making available their model output. For CMIP the U.S. Department of Energy's Program for Climate Model Diagnosis and Intercomparison provides coordinating support and led development of software infrastructure in partnership with the Global Organization for Earth System Science Portals.

- We acknowledge the MODIS/TERRA project for the NPP data, acquired from http://neo.sci.gsfc.nasa.gov/view.php? datasetId=MOD17A2_M_PSN\&year=2001.

- Data from the RAPID-WATCH MOC monitoring project are funded by the Natural Environment Research Council and are freely available from http://www.rapid.ac.uk/rapidmoc.

- The simulations' output for the experiments used in this paper can be accessed from the BRIDGE website at http://www.paleo.bristol.ac.uk/ummodel/scripts/papers/ Valdes_et_al_2017.html.

\section{The Supplement related to this article is available online at https://doi.org/10.5194/gmd-10-3715-2017- supplement.}

Competing interests. The authors declare that they have no conflict of interest.
Acknowledgements. - The efforts of all of the developers of HadCM3 at the Hadley Centre and UK Met Office is gratefully acknowledged. Without their hard and successful work we would not be able to tackle some important scientific problems.

- Climate simulations were carried out using the computational facilities of the Advanced Computing Research Centre, University of Bristol (http://www.bris.ac.uk/acrc) (Bluecrystal)

- Edward Armstrong was funded by NERC (NE/L501554/1).

- Marcus P. S. Badger was funded by NERC (NE/J008591/1).

- Taraka Davies-Barnard was funded by the European Commission's Seventh Framework Program grant agreement 282672 (EMBRACE) and EU grant ERC-2013-CoG-617313 (PaleoGenie).

- Alex Farnsworth was funded by NERC (NE/K014757/1; NE/I005722/1; NE/I005714/1)

- Peter O. Hopcroft was funded by NERC (NE/I010912/1).

- Alan T. Kennedy was funded by NERC (NE/L002434/1).

- Natalie S. Lord was funded by RWM Limited via a framework contract with Amec Foster Wheeler, who were supported by Quintessa.

- Alice Marzocchi was funded by National Science Foundation (NSF) award no. 1536454

- William H. G. Roberts was funded by the Leverhulme Trust.

- Gregory J. L. Tourte was funded through "The Greenhouse Earth System" advanced ERC grant (T-GRES, project reference 340923), awarded to Richard D. Pancost.

Edited by: Paul Halloran

Reviewed by: Christopher Brierley and two anonymous referees

\section{References}

Adam, J. C., Clark, E. A., Lettenmaier, D. P., and Wood, E. F.: Correction of Global Precipitation Products for Orographic Effects, J. Climate, 19, 15-38, https://doi.org/10.1175/JCLI3604.1, 2006. Antonov, J. I., Seidov, D., Boyer, T. P., Locarnini, R. A., Mishonov, A. V., Garcia, H. E., Baranova, O. K., Zweng, M. M., and Johnson, D. R.: Volume 2: Salinity, World Ocean Atlas 2009, NOAA Atlas NESDIS, U.S. Government Printing Office, Washington, D.C., 2010.

Arakawa, A. and Lamb, V. R.: Computational Design of the Basic Dynamical Processes of the UCLA General Circulation Model, in: General Circulation Models of the Atmosphere, edited by: Chang, J., Vol. 17, Methods in Computational Physics: Advances in Research and Applications, 173-265, Elsevier, https://doi.org/10.1016/B978-0-12-460817-7.50009-4, 1977.

Armstrong, E., Valdes, P., House, J., and Singarayer, J.: The Role of $\mathrm{CO}_{2}$ and Dynamic Vegetation on the Impact of Temperate LandUse Change in the HadCM3 Coupled Climate Model, Earth Interact., 20, 1-20, https://doi.org/10.1175/EI-D-15-0036.1, 2016.

Arnell, N. W., Hudson, D. A., and Jones, R. G.: Climate change scenarios from a regional climate model: Estimating change in runoff in southern Africa, J. Geophys. Res.-Atmos., 108, 4519 , https://doi.org/10.1029/2002JD002782, 2003. 
Beerling, D. J., Fox, A., Stevenson, D. S., and Valdes, P. J.: Enhanced chemistry-climate feedbacks in past greenhouse worlds, P. Natl. Acad. Sci. USA, 108, 9770-9774, https://doi.org/10.1073/pnas.1102409108, 2011.

Best, M. J., Pryor, M., Clark, D. B., Rooney, G. G., Essery, R. L. H., Ménard, C. B., Edwards, J. M., Hendry, M. A., Porson, A., Gedney, N., Mercado, L. M., Sitch, S., Blyth, E., Boucher, O., Cox, P. M., Grimmond, C. S. B., and Harding, R. J.: The Joint UK Land Environment Simulator (JULES), model description Part 1: Energy and water fluxes, Geosci. Model Dev., 4, 677-699, https://doi.org/10.5194/gmd-4-677-2011, 2011.

Betts, R. A., Cox, P. M., Collins, M., Harris, P. P., Huntingford, C., and Jones, C. D.: The role of ecosystem-atmosphere interactions in simulated Amazonian precipitation decrease and forest dieback under global climate warming, Theor. Appl. Climatol., 78, 157-175, 2004.

Bhaskaran, B., Jones, R. G., Murphy, J. M., and Noguer, M.: Simulations of the Indian summer monsoon using a nested regional climate model: domain size experiments, Clim. Dynam., 12, 573-587, https://doi.org/10.1007/BF00216267, 1996

Booth, B. B. B., Jones, C. D., Collins, M., Totterdell, I. J., Cox, P. M., Sitch, S., Huntingford, C., Betts, R. A., Harris, G. R., and Lloyd, J.: High sensitivity of future global warming to land carbon cycle processes, Environ. Res. Lett., 7, 024002, https://doi.org/10.1088/1748-9326/7/2/024002, 2012.

Braconnot, P., Otto-Bliesner, B., Harrison, S., Joussaume, S., Peterchmitt, J.-Y., Abe-Ouchi, A., Crucifix, M., Driesschaert, E., Fichefet, Th., Hewitt, C. D., Kageyama, M., Kitoh, A., Laîné, A., Loutre, M.-F., Marti, O., Merkel, U., Ramstein, G., Valdes, P., Weber, S. L., Yu, Y., and Zhao, Y.: Results of PMIP2 coupled simulations of the Mid-Holocene and Last Glacial Maximum Part 1: experiments and large-scale features, Clim. Past, 3, 261277, https://doi.org/10.5194/cp-3-261-2007, 2007.

Bradshaw, C. D., Lunt, D. J., Flecker, R., and Davies-Barnard, T.: Disentangling the roles of late Miocene palaeogeography and vegetation - Implications for climate sensitivity, Palaeogeogr. Palaeocl., 417, 17-34, 2015.

Bragg, F. J., Lunt, D. J., and Haywood, A. M.: Mid-Pliocene climate modelled using the UK Hadley Centre Model: PlioMIP Experiments 1 and 2, Geosci. Model Dev., 5, 1109-1125, https://doi.org/10.5194/gmd-5-1109-2012, 2012.

Brooks, R. H. and Corey, A. T.: Hydraulic properties of porous media, Hydrology Papers, Colorado State University, Fort Collins, Co, 3, 1964 .

Bryan, K. and Cox, M. D.: An Approximate Equation of State for Numerical Models of Ocean Circulation, J. Phys. Oceanogr., 2, 510-514, https://doi.org/10.1175/15200485(1972)002<0510:AAEOSF>2.0.CO;2, 1972.

Bushell, A.: Unified Model User Guide, chap. Clouds, p. 27, in: Matthews (1998), available at: http://www.ukscience.org/ _Media/UM_User_Guide.pdf (last access: 8 September 2017), 1998.

Clark, D. B., Mercado, L. M., Sitch, S., Jones, C. D., Gedney, N., Best, M. J., Pryor, M., Rooney, G. G., Essery, R. L. H., Blyth, E., Boucher, O., Harding, R. J., Huntingford, C., and Cox, P. M.: The Joint UK Land Environment Simulator (JULES), model description - Part 2: Carbon fluxes and vegetation dynamics, Geosci. Model Dev., 4, 701-722, https://doi.org/10.5194/gmd-4701-2011, 2011.
Claussen, M., Mysak, L., Weaver, A., Crucifix, M., Fichefet, T., Loutre, M.-F., Weber, S., Alcamo, J., Alexeev, V., Berger, A., Calov, R., Ganopolski, A., Goosse, H., Lohmann, G., Lunkeit, F., Mokhov, I., Petoukhov, V., Stone, P., and Wang, Z.: Earth system models of intermediate complexity: closing the gap in the spectrum of climate system models, Clim. Dynam., 18, 579-586, https://doi.org/10.1007/s00382-001-0200-1, 2002.

Collins, M., Tett, S. F. B., and Cooper, C.: The internal climate variability of HadCM3, a version of the Hadley Centre coupled model without flux adjustments, Clim. Dynam., 17, 61-81, https://doi.org/10.1007/s003820000094, 2001.

Collins, W. J., Bellouin, N., Doutriaux-Boucher, M., Gedney, N., Halloran, P., Hinton, T., Hughes, J., Jones, C. D., Joshi, M., Liddicoat, S., Martin, G., O'Connor, F., Rae, J., Senior, C., Sitch, S., Totterdell, I., Wiltshire, A., and Woodward, S.: Development and evaluation of an Earth-System model - HadGEM2, Geosci. Model Dev., 4, 1051-1075, https://doi.org/10.5194/gmd-4-10512011, 2011.

Cox, P. M.: A primitive equation, 3-dimensional model of the ocean, GFDL Ocean Group Technical Report No. 1, Geophysical Fluid Dynamics Laboratory, Princeton, New Jersey, 1984.

Cox, P. M.: Description of the TRIFFID dynamic global vegetation model, Tech. rep., Met Office Hadley Centre, Exeter, UK, 2001.

Cox, P. M., Huntingford, C., and Harding, R. J.: A canopy conductance and photosynthesis model for use in a GCM land surface scheme, J. Hydrol., 212-213, 79-94, https://doi.org/10.1016/S0022-1694(98)00203-0, 1998.

Cox, P. M., Betts, R. A., Bunton, C. B., Essery, R. L. H., Rowntree, P. R., and Smith, J.: The impact of new land surface physics on the GCM simulation of climate and climate sensitivity, Clim. Dynam., 15, 183-203, https://doi.org/10.1007/s003820050276, 1999.

Cox, P. M., Betts, R. A., Jones, C. D., Spall, S. A., and Totterdell, I. J.: Acceleration of global warming due to carbon-cycle feedbacks in a coupled climate model, Nature, 408, 184-187, https://doi.org/10.1038/35041539, 2000.

Cusack, S., Slingo, A., Edwards, J. M., and Wild, M.: The radiative impact of a simple aerosol climatology on the Hadley Centre atmospheric GCM, Q. J. Roy. Meteor. Soc., 124, 2517-2526, https://doi.org/10.1002/qj.49712455117, 1998.

Davies-Barnard, T., Valdes, P. J., Jones, C. D., and Singarayer, J. S.: Sensitivity of a coupled climate model to canopy interception capacity, Clim. Dynam., 42, 1715-1732, https://doi.org/10.1007/s00382-014-2100-1, 2014.

Day, J. J., Bamber, J. L., Valdes, P. J., and Kohler, J.: The impact of a seasonally ice free Arctic Ocean on the temperature, precipitation and surface mass balance of Svalbard, The Cryosphere, 6, 35-50, https://doi.org/10.5194/tc-6-35-2012, 2012.

Day, J. J., Bamber, J. L., and Valdes, P. J.: The Greenland Ice Sheet's surface mass balance in a seasonally sea ice-free Arctic, J. Geophys. Res.-Earth, 118, 1533-1544, https://doi.org/10.1002/jgrf.20112, 2013.

Demory, M.-E., Vidale, P. L., Roberts, M. J., Berrisford, P., Strachan, J., Schiemann, R., and Mizielinski, M. S.: The role of horizontal resolution in simulating drivers of the global hydrological cycle, Clim. Dynam., 42, 2201-2225, https://doi.org/10.1007/s00382-013-1924-4, 2014.

Dolan, A. M., Haywood, A. M., Hunter, S. J., Tindall, J. C., Dowsett, H. J., Hill, D. J., and Pickering, S. J.: Mod- 
elling the enigmatic Late Pliocene Glacial Event - Marine Isotope Stage M2, Global Planet. Change, 128, 47-60, https://doi.org/10.1016/j.gloplacha.2015.02.001, 2015.

Durman, C. F., Gregory, J. M., Hassell, D. C., Jones, R. G., and Murphy, J. M.: A comparison of extreme European daily precipitation simulated by a global and a regional climate model for present and future climates, Q. J. Roy. Meteor. Soc., 127, 10051015, https://doi.org/10.1002/qj.49712757316, 2001.

Edwards, J.: "Radiation" Unified Model User Guide, Version 4.4., Report, The Meteorological Office, UK, Bracknell, Berkshire, UK, available at: http://www.ukscience.org/_Media/UM_User_ Guide.pdf (last access: 8 September 2017), 1998.

Edwards, J. M. and Slingo, A.: Studies with a flexible new radiation code. I: Choosing a configuration for a largescale model, Q. J. Roy. Meteor. Soc., 122, 689-719, https://doi.org/10.1002/qj.49712253107, 1996.

Edwards, M. O.: Global gridded elevation and bathymetry on 5minute geographic grid (ETOPO5), NOAA, National Geophysical Data Center, 1989.

Essery, R. L. H., Best, M. J., and Cox, P. M.: MOSES 2.2 Technical Documentation, Tech. rep., Hadley Centre, Met Office, 2001.

Essery, R. L. H., Best, M. J., Betts, R. A., Cox, P. M., and Taylor, C. M.: Explicit Representation of Subgrid Heterogeneity in a GCM Land Surface Scheme, J. Hydrometeorol., 4, 530-543, https://doi.org/10.1175/15257541(2003)004<0530:EROSHI>2.0.CO;2, 2003.

Eyring, V., Bony, S., Meehl, G. A., Senior, C. A., Stevens, B., Stouffer, R. J., and Taylor, K. E.: Overview of the Coupled Model Intercomparison Project Phase 6 (CMIP6) experimental design and organization, Geosci. Model Dev., 9, 1937-1958, https://doi.org/10.5194/gmd-9-1937-2016, 2016a.

Eyring, V., Righi, M., Lauer, A., Evaldsson, M., Wenzel, S., Jones, C., Anav, A., Andrews, O., Cionni, I., Davin, E. L., Deser, C., Ehbrecht, C., Friedlingstein, P., Gleckler, P., Gottschaldt, K.D., Hagemann, S., Juckes, M., Kindermann, S., Krasting, J., Kunert, D., Levine, R., Loew, A., Mäkelä, J., Martin, G., Mason, E., Phillips, A. S., Read, S., Rio, C., Roehrig, R., Senftleben, D., Sterl, A., van Ulft, L. H., Walton, J., Wang, S., and Williams, K. D.: ESMValTool (v1.0) - a community diagnostic and performance metrics tool for routine evaluation of Earth system models in CMIP, Geosci. Model Dev., 9, 1747-1802, https://doi.org/10.5194/gmd-9-1747-2016, 2016b.

Ferraro, R., Waliser, D. E., Glecker, P., Taylor, K. E., and Eyring, V.: Evolving obs4MIPS to support the Sixth Coupled Model Intercomparison Project (CMIP6), Am. Metereol. Soc., 131-133, https://doi.org/10.1175/BAMS-D-14-00216.1, 2015.

Flato, G., Marotzke, J., Abiodun, B., Braconnot, P., Chou, S., Collins, W., Cox, P. M., Driouech, F., Emori, S., Eyring, V., Forest, C., Gleckler, P., Guilyardi, E., Jakob, C., Kattsov, V., Reason, C., and Rummukainen, M.: Evaluation of Climate Models, in: Climate Change 2013: The Physical Science Basis. Contribution of Working Group I to the Fifth Assessment Report of the Intergovernmental Panel on Climate Change, edited by: Stocker, T., Qin, D., Plattner, G.-K., Tignor, M., Allen, S., Boschung, J., Nauels, A., Xia, Y., Bex, V., and Midgley, P., chap. 9, 741-866, Cambridge University Press, Cambridge, UK and New York, NY, USA, https://doi.org/10.1017/CBO9781107415324.020, 2013.

Foreman, S. J.: Unified Model Documentaiton Paper Number 40, The Ocean Model, Report, The Met. Office, available at: http://cms.ncas.ac.uk/documents/vn4.5/p040.pdf (last access: 8 September 2017), 2005.

Gent, P. R. and McWilliams, J. C.: Isopycnal Mixing in Ocean Circulation Models, J. Phys. Oceanogr., 20, 150-155, 1990.

Gleckler, P. J., Taylor, K. E., and Doutriaux, C.: Performance metrics for climate models, J. Geophys. Res.-Atmos., 113, d06104, https://doi.org/10.1029/2007JD008972, 2008.

Goosse, H., Brovkin, V., Fichefet, T., Haarsma, R., Huybrechts, P., Jongma, J., Mouchet, A., Selten, F., Barriat, P.-Y., Campin, J.M., Deleersnijder, E., Driesschaert, E., Goelzer, H., Janssens, I., Loutre, M.-F., Morales Maqueda, M. A., Opsteegh, T., Mathieu, P.-P., Munhoven, G., Pettersson, E. J., Renssen, H., Roche, D. M., Schaeffer, M., Tartinville, B., Timmermann, A., and Weber, S. L.: Description of the Earth system model of intermediate complexity LOVECLIM version 1.2, Geosci. Model Dev., 3, 603-633, https://doi.org/10.5194/gmd-3-603-2010, 2010.

Gordon, C., Cooper, C., Senior, C. A., Banks, H., Gregory, J. M., Johns, T. C., Mitchell, J. F. B., and Wood, R. A.: The simulation of SST, sea ice extents and ocean heat transports in a version of the Hadley Centre coupled model without flux adjustments, Clim. Dynam., 16, 147-168, https://doi.org/10.1007/s003820050010, 2000.

Grant, A.: Unified Model User Guide, chap. Convection, p. 32, in: Matthews (1998), available at: http://www.ukscience.org/ _Media/UM_User_Guide.pdf (last access: 8 September 2017), 1998.

Gregory, D., Kershaw, R., and Inness, P. M.: Parametrization of momentum transport by convection. II: Tests in single-column and general circulation models, Q. J. Roy. Meteor. Soc., 123, 1153 1183, https://doi.org/10.1002/qj.49712354103, 1997.

Gregory, D., Shutts, G. J., and Mitchell, J. R.: A new gravity-wavedrag scheme incorporating anisotropic orography and low-level wave breaking: Impact upon the climate of the UK Meteorological Office Unified Model, Q. J. Roy. Meteor. Soc., 124, 463-493, https://doi.org/10.1002/qj.49712454606, 1998.

Gregory, J. M., Ingram, W. J., Palmer, M. A., Jones, G. S., Stott, P. A., Thorpe, R. B., Lowe, J. A., Johns, T. C., and Williams, K. D.: A new method for diagnosing radiative forcing and climate sensitivity, Geophys. Res. Lett., 31, L03205, https://doi.org/10.1029/2003gl018747, 2004.

Gregory, J. M., Browne, O. J. H., Payne, A. J., Ridley, J. K., and Rutt, I. C.: Modelling large-scale ice-sheet-climate interactions following glacial inception, Clim. Past, 8, 1565-1580, https://doi.org/10.5194/cp-8-1565-2012, 2012.

Griffies, S., Gnanadesikan, A., Pacanowski, R., Larichev, V. D., Dukowicz, J. K., and Smith, R. D.: Oceanic isopycnal mixing by coordinate rotation, J. Phys. Oceanogr., 28, 805-830, 1998.

The HadGEM2 Development Team: G. M. Martin, Bellouin, N., Collins, W. J., Culverwell, I. D., Halloran, P. R., Hardiman, S. C., Hinton, T. J., Jones, C. D., McDonald, R. E., McLaren, A. J., O'Connor, F. M., Roberts, M. J., Rodriguez, J. M., Woodward, S., Best, M. J., Brooks, M. E., Brown, A. R., Butchart, N., Dearden, C., Derbyshire, S. H., Dharssi, I., Doutriaux-Boucher, M., Edwards, J. M., Falloon, P. D., Gedney, N., Gray, L. J., Hewitt, H. T., Hobson, M., Huddleston, M. R., Hughes, J., Ineson, S., Ingram, W. J., James, P. M., Johns, T. C., Johnson, C. E., Jones, A., Jones, C. P., Joshi, M. M., Keen, A. B., Liddicoat, S., Lock, A. P., Maidens, A. V., Manners, J. C., Milton, S. F., Rae, J. G. L., Ridley, J. K., Sellar, A., Senior, C. A., Totterdell, I. J., Verhoef, A., 
Vidale, P. L., and Wiltshire, A.: The HadGEM2 family of Met Office Unified Model climate configurations, Geosci. Model Dev., 4, 723-757, https://doi.org/10.5194/gmd-4-723-2011, 2011.

Hawkins, E., Smith, R. S., Allison, L. C., Gregory, J. M., Woollings, T. J., Pohlmann, H., and de Cuevas, B.: Bistability of the Atlantic overturning circulation in a global climate model and links to ocean freshwater transport, Geophys. Res. Lett., 38, L10605, https://doi.org/10.1029/2011g1047208, 2011.

Haywood, A. M., Valdes, P. J., and Markwick, P. J.: Cretaceous (Wealden) climates: a modelling perspective, Cretaceous Res., 25, 303-311, https://doi.org/10.1016/j.cretres.2004.01.005, 2004.

Hewitt, C. D., Broccoli, A. J., Mitchell, J. F. B., and Stouffer, R. J.: A coupled model study of the Last Glacial Maximum: Was part of the North Atlantic relatively warm?, Geophys. Res. Lett., 28, 1571-1574, https://doi.org/10.1029/2000GL012575, 2001.

Hibler, W. D.: A Dynamic Thermodynamic Sea Ice Model, J. Phys. Oceanogr., 9, 815-846, https://doi.org/10.1175/15200485(1979)009<0815:ADTSIM>2.0.CO;2, 1979.

Hopcroft, P. O., Valdes, P. J., Wania, R., and Beerling, D. J.: Limited response of peatland $\mathrm{CH}_{4}$ emissions to abrupt Atlantic Ocean circulation changes in glacial climates, Clim. Past, 10, 137-154, https://doi.org/10.5194/cp-10-137-2014, 2014.

Hudson, D. A. and Jones, R. G.: Regional Climate Models Simulations of Present-Day and Future Climate over Southern Africa, Tech. rep., Met Office Hadley Center, Exeter, UK, available at: https://digital.nmla.metoffice.gov.uk/download/file/sdb: digitalFilela55db57e-b268-49ba-9cc3-d48553b244f5/ (last access: 8 September 2017), 2002.

Hughes, J. K., Valdes, P. J., and Betts, R. A.: Dynamics of a global-scale vegetation model, Ecol. Model., 198, 452-462, https://doi.org/10.1016/j.ecolmodel.2006.05.020, 2006.

Ingram, W. S., Woodward, S., and Edwards, J.: Unified Model Documentation Paper: Radiation, Report 23, The Meteorological Office, UK, 1997.

IPCC: Climate Change 2007: The Physical Science Basis. Contribution of Working Group I to the Fourth Assessment Report of the Intergovernmental Panel on Climate Change, edited by: Solomon, S., Qin, D., Manning, M., Chen, Z., Marquis, M., Avery, K., Tignor, M., and Miller, H., Cambridge University Press, 2007.

Irvine, P. J., Ridgwell, A., and Lunt, D. J.: Assessing the regional disparities in geoengineering impacts, Geophys. Res. Lett., 37, L18702, https://doi.org/10.1029/2010GL044447, 2010.

Jackson, L. and Vellinga, M.: Multidecadal to Centennial Variability of the AMOC: HadCM3 and a Perturbed Physics Ensemble, J. Climate, 26, 2390-2407, https://doi.org/10.1175/JCLI-D-1100601.1, 2013

Johns, T. C., Gregory, J. M., Ingram, W. J., Johnson, C. E., Lowe, J. A., Mitchell, J. F. B., Roberts, D. L., Sexton, D. M. H., Stevenson, D., Tett, S. F. B., and Woodage, M. J.: Anthropogenic climate change for 1860 to 2100 simulated with the HadCM3 model under updated emissions scenarios, Clim. Dynam., 20, 583-612, https://doi.org/10.1007/s00382-002-0296-y, 2003.

Jones, C.: A Fast Ocean GCM without Flux Adjustments, J. Atmos. Ocean. Technol., 20, 1857-1868, https://doi.org/10.1175/15200426(2003)020<1857:AFOGWF>2.0.CO;2, 2003.

Jones, C., Gregory, J., Thorpe, R., Cox, P., Murphy, J., Sexton, D., and Valdes, P. J.: Systematic optimisation and climate simulation of FAMOUS, a fast version of HadCM3, Clim. Dynam., 25, 189204, https://doi.org/10.1007/s00382-005-0027-2, 2005.

Jones, R. G., Murphy, J. M., and Noguer, M.: Simulation of climate change over europe using a nested regional-climate model. I: Assessment of control climate, including sensitivity to location of lateral boundaries, Q. J. Roy. Meteor. Soc., 121, 1413-1449, https://doi.org/10.1002/qj.49712152610, 1995.

Kennedy, A. T., Farnsworth, A., Lunt, D. J., Lear, C. H., and Markwick, P. J.: Atmospheric and oceanic impacts of Antarctic glaciation across the Eocene-Oligocene transition, Philos. T. R. Soc., A, 373, 20140419, https://doi.org/10.1098/rsta.2014.0419, 2015.

Kraus, E. B. and Turner, J. S.: A one-dimensional model of the seasonal thermocline II. The general theory and its consequences, Tellus, 19, 98-106, https://doi.org/10.1111/j.21533490.1967.tb01462.x, 1967.

Large, W. G., McWilliams, J. C., and Doney, S. C.: Oceanic vertical mixing: A review and a model with a nonlocal boundary layer parameterization, Rev. Geophys., 32, 363-403, https://doi.org/10.1029/94RG01872, 1994.

Legg, S., Briegleb, B., Chang, Y., Chassignet, E. P., Danabasoglu, G., Ezer, T., Gordon, A. L., Griffies, S., Hallberg, R., Jackson, L., Large, W., Ozgokmen, T. M., Peters, H., Price, J., Riemenschneider, U., Wu, W. L., Xu, X. B., and Yang, J. Y.: Improving Oceanic Overflow Representation in Climate Models: The Gravity Current Entrainment Climate Process Team, B. Am. Meteorol. Soc., 90, 657-670, https://doi.org/10.1175/2008bams2667.1, 2009.

Liu, W., Liu, Z. Y., and Brady, E. C.: Why is the AMOC Monostable in Coupled General Circulation Models?, J. Climate, 27, 24272443, https://doi.org/10.1175/Jcli-D-13-00264.1, 2014.

Locarnini, R. A., Mishonov, A. V., Antonov, J. I., Boyer, T. P., Garcia, H. E., Baranova, O. K., Zweng, M. M., and Johnson, D. R.: Volume 1: Temperature, World Ocean Atlas 2009, NOAA Atlas NESDIS, U.S. Government Printing Office, Washington, D.C., 2010.

Loeb, N., Wang, H., Cheng, A., Kato, S., Fasullo, J., Xu, K.-M., and Allan, R.: Observational constraints on atmospheric and oceanic cross-equatorial heat transports: revisiting the precipitation asymmetry problem in climate models, Clim. Dynam., 46 , 3239-3257, https://doi.org/10.1007/s00382-015-2766-z, 2016.

Loptson, C. A., Lunt, D. J., and Francis, J. E.: Investigating vegetation-climate feedbacks during the early Eocene, Clim. Past, 10, 419-436, https://doi.org/10.5194/cp-10-4192014, 2014.

Loveland, T. R. and Belward, A. S.: The IGBP-DIS global $1 \mathrm{~km}$ land cover data set, DISCover: First results, Int. J. Remote Sens., 18, 3289-3295, https://doi.org/10.1080/014311697217099, 1997.

Lunt, D. J., Ridgwell, A., Valdes, P. J., and Seale, A.: "Sunshade World": A fully coupled GCM evaluation of the climatic impacts of geoengineering, Geophys. Res. Lett., 35, L12710, https://doi.org/10.1029/2008GL033674, 2008.

Lunt, D. J., Farnsworth, A., Loptson, C., Foster, G. L., Markwick, P., O'Brien, C. L., Pancost, R. D., Robinson, S. A., and Wrobel, N.: Palaeogeographic controls on climate and proxy interpretation, Clim. Past, 12, 1181-1198, https://doi.org/10.5194/cp-12-11812016, 2016.

Malhi, Y., Aragão, L. E. O. C., Galbraith, D., Huntingford, C., Fisher, R., Zelazowski, P., Sitch, S., McSweeney, C., and Meir, P.: Exploring the likelihood and mechanism of a climate-change- 
induced dieback of the Amazon rainforest, P. Natl. Acad. Sci., 106, 20610-20615, https://doi.org/10.1073/pnas.0804619106, 2009.

Marzocchi, A., Hirschi, J. J.-M., Holliday, N. P., Cunningham, S. A., Blaker, A. T., and Coward, A. C.: The North Atlantic subpolar circulation in an eddy-resolving global ocean model, J. Marine Syst., 142, 126-143, https://doi.org/10.1016/j.jmarsys.2014.10.007, 2015a.

Marzocchi, A., Lunt, D. J., Flecker, R., Bradshaw, C. D., Farnsworth, A., and Hilgen, F. J.: Orbital control on late Miocene climate and the North African monsoon: insight from an ensemble of sub-precessional simulations, Clim. Past, 11, 1271-1295, https://doi.org/10.5194/cp-11-1271-2015, $2015 \mathrm{~b}$.

Matthews, D. (Ed.): Unified Model User Guide, The Meteorological Office, Bracknell, Berkshire, UK, available at: http: //www.ukscience.org/_Media/UM_User_Guide.pdf (last access: 8 September 2017), 1998.

McCarthy, G., Frajka-Williams, E., Johns, W. E., Baringer, M. O., Meinen, C. S., Bryden, H. L., Rayner, D., Duchez, A., Roberts, C., and Cunningham, S. A.: Observed interannual variability of the Atlantic meridional overturning circulation at $26.5^{\circ} \mathrm{N}$, Geophys. Res. Lett., 39, https://doi.org/10.1029/2012gl052933, 2012.

Msadek, R., Johns, W. E., Yeager, S. G., Danabasoglu, G., Delworth, T. L., and Rosati, A.: The Atlantic Meridional Heat Transport at $26.5^{\circ} \mathrm{N}$ and Its Relationship with the MOC in the RAPID Array and the GFDL and NCAR Coupled Models, J. Climate, 26, 4335-4356, https://doi.org/10.1175/Jcli-D-12-00081.1, 2013.

Murphy, J. M., Booth, B. B. B., Collins, M., Harris, G. R., Sexton, D. M. H., and Webb, M. J.: A methodology for probabilistic predictions of regional climate change from perturbed physics ensembles, Philos. T. R. Soc. Lond. A, 365, 1993-2028, https://doi.org/10.1098/rsta.2007.2077, 2007.

New, M., Lister, D., Hulme, M., and Makin, I.: A high-resolution data set of surface climate over global land areas, Clim. Res., 21, 1-25, https://doi.org/10.3354/cr021001, 2002.

Pacanowski, R. and Philander, S.: Parametrisation of vertical mixing in numerical models of tropical oceans, J. Phys. Oceanogr., 11, 1443-1451, 1981.

Pardaens, A. K., Banks, H. T., Gregory, J. M., and Rowntree, P. R.: Freshwater transports in HadCM3, Clim. Dynam., 21, 177-195, https://doi.org/10.1007/s00382-003-0324-6, 2003.

Pope, V. D., Gallani, M. L., Rowntree, P. R., and Stratton, R. A.: The impact of new physical parametrizations in the Hadley Centre climate model: HadAM3, Clim. Dynam., 16, 123-146, https://doi.org/10.1007/s003820050009, 2000.

Ramankutty, N. and Foley, J. A.: Estimating historical changes in global land cover: Croplands from 1700 to 1992, Global Biogeochem. Cy., 13, 997-1027, https://doi.org/10.1029/1999GB900046, 1999.

Redi, M. H.: Oceanic Isopycnal Mixing by Coordinate Rotation, J. Phys. Oceanogr., 12, 1154-1158, https://doi.org/10.1175/15200485(1982)012<1154:OIMBCR>2.0.CO;2, 1998.

Reichler, T. and Kim, J.: How well do coupled models simulate today's climate?, B. Am. Meteorol. Soc., 89, 303-311, https://doi.org/10.1175/BAMS-89-3-303, 2008.

Rickard, G.: Unified Model Documentation No. 59: Ocean Models and the Implementation of Vertical Diffusion and Vertical Mixing, Report, The Met. Office, available at: http://cms.ncas.ac. uk/documents/vn4.5/p059.pdf (last access: 8 September 2017), 1999.

Ridgwell, A., Singarayer, J. S., Hetherington, A. M., and Valdes, P. J.: Tackling Regional Climate Change By Leaf Albedo Bio-geoengineering, Curr. Biol., 19, 146-150, https://doi.org/10.1016/j.cub.2008.12.025, 2009.

Ridley, J. K., Huybrechts, P., Gregory, J. M., and Lowe, J. A.: Elimination of the Greenland ice sheet in a high $\mathrm{CO}_{2}$ climate, J. Climate, 18, 3409-3427, https://doi.org/10.1175/Jcli3482.1, 2005.

Roberts, C. D., Garry, F. K., and Jackson, L. C.: A Multimodel Study of Sea Surface Temperature and Subsurface Density Fingerprints of the Atlantic Meridional Overturning Circulation, J. Climate, 26, 9155-9174, https://doi.org/10.1175/Jcli-D-12$00762.1,2013$

Roberts, W. H. G. and Valdes, P. J.: Green Mountains and White Plains: the effect of Northern Hemisphere ice sheets on the global energy budget, J. Climate., 30, 3887-3905, https://doi.org/10.1175/JCLI-D-15-0846.1, 2017.

Roberts, W. H. G., Valdes, P. J., and Payne, A. J.: Topography's crucial role in Heinrich Events, P. Natl. Acad. Sci. USA, 111, 16688-16693, https://doi.org/10.1073/pnas.1414882111, 2014.

Balan Sarojini, B., Gregory, J. M., Tailleux, R., Bigg, G. R., Blaker, A. T., Cameron, D. R., Edwards, N. R., Megann, A. P., Shaffrey, L. C., and Sinha, B.: High frequency variability of the Atlantic meridional overturning circulation, Ocean Sci., 7, 471486, https://doi.org/10.5194/os-7-471-2011, 2011.

Schaller, N., Kay, A. L., Lamb, R., Massey, N. R., van Oldenborgh, G. J., Otto, F. E. L., Sparrow, S. N., Vautard, R., Yiou, P., Ashpole, I., Bowery, A., Crooks, S. M., Haustein, K., Huntingford, C., Ingram, W. J., Jones, R. G., Legg, T., Miller, J., Skeggs, J., Wallom, D., Weisheimer, A., Wilson, S., Stott, P. A., and Allen, M. R.: Human influence on climate in the 2014 southern England winter floods and their impacts, Nature Clim. Change, 6, 627-634, https://doi.org/10.1038/nclimate2927, 2016.

Sijp, W. P.: Characterising meridional overturning bistability using a minimal set of state variables, Clim. Dynam., 39, 2127-2142, https://doi.org/10.1007/s00382-011-1249-0, 2012.

Simmons, A. J. and Strüfing, R.: Numerical forecasts of stratospheric warming events using a model with a hybrid vertical coordinate, Q. J. Roy. Meteor. Soc., 109, 81-111, https://doi.org/10.1002/qj.49710945905, 1983.

Singarayer, J. S. and Valdes, P. J.: High-latitude climate sensitivity to ice-sheet forcing over the last $120 \mathrm{kyr}$, Quaternary Sci. Rev., 29, 43-55, https://doi.org/10.1016/j.quascirev.2009.10.011, 2010.

Singarayer, J. S., Ridgwell, A., and Irvine, P.: Assessing the benefits of crop albedo bio-geoengineering, Environ. Res. Lett., 4, 045110, https://doi.org/10.1088/1748-9326/4/4/045110, 2009.

Sitch, S., Huntingford, C., Gedney, N., Levy, P. E., Lomas, M., Piao, S. L., Betts, R., Ciais, P., Cox, P. M., Friedlingstein, P., Jones, C. D., Prentice, I. C., and Woodward, F. I.: Evaluation of the terrestrial carbon cycle, future plant geography and climate-carbon cycle feedbacks using five Dynamic Global Vegetation Models (DGVMs), Glob. Change Biol., 14, 2015-2039, https://doi.org/10.1111/j.1365-2486.2008.01626.x, 2008.

Smeed, D., McCarthy, G., Rayner, D., Moat, B. I., Johns, W. E., Baringer, M., and Meinen, C. S.: Atlantic meridional overturning circulation observed by the RAPID-MOCHA-WBTS (RAPIDMeridional Overturning Circulation and Heatflux Array-Western 
Boundary Time Series) array at 26N from 2004 to 2014, British Oceanographic Data Centre - Natural Environment Research Council, UK, https://doi.org/10/6qb, 2015.

Smith, D. M., Cusack, S., Colman, A. W., Folland, C. K., Harris, G. R., and Murphy, J. M.: Improved Surface Temperature Prediction for the Coming Decade from a Global Climate Model, Science, 317, 796-799, https://doi.org/10.1126/science.1139540, 2007.

Smith, D. M., Eade, R., Dunstone, N. J., Fereday, D., Murphy, J. M., Pohlmann, H., and Scaife, A. A.: Skilful multi-year predictions of Atlantic hurricane frequency, Nat. Geosci., 3, 846-849, https://doi.org/10.1038/ngeo1004, 2010.

Smith, R. S.: The FAMOUS climate model (versions XFXWB and XFHCC): description update to version XDBUA, Geosci. Model Dev., 5, 269-276, https://doi.org/10.5194/gmd-5-2692012, 2012.

Smith, R. S., Gregory, J. M., and Osprey, A.: A description of the FAMOUS (version XDBUA) climate model and control run, Geosci. Model Dev., 1, 53-68, https://doi.org/10.5194/gmd-153-2008, 2008.

Spencer, H., Sutton, R., and Slingo, J. M.: El Niño in a Coupled Climate Model: Sensitivity to Changes in Mean State Induced by Heat Flux and Wind Stress Corrections, J. Climate, 20, 2273 2298, https://doi.org/10.1175/JCLI4111.1, 2007.

Stainforth, D. A., Aina, T., Christensen, C., Collins, M., Faull, N., Frame, D. J., Kettleborough, J. A., Knight, S., Martin, A., Murphy, J. M., Piani, C., Sexton, D., Smith, L. A., Spicer, R. A., Thorpe, A. J., and Allen, M. R.: Uncertainty in predictions of the climate response to rising levels of greenhouse gases, Nature, 433, 403-406, https://doi.org/10.1038/nature03301, 2005.

Stott, P. A. and Kettleborough, J. A.: Origins and estimates of uncertainty in predictions of twenty-first century temperature rise, Nature, 416, 723-726, 2002.

Stott, P. A., Tett, S. F. B., Jones, G. S., Allen, M. R., Mitchell, J. F. B., and Jenkins, G. J.: External control of 20th century temperature by natural and anthropogenic forcings, Science, 290, 2133 2137, 2000.

Svirezhev, Y. M.: Thermodynamics and ecology, Ecol. Model., 132, 11-22, https://doi.org/10.1016/S0304-3800(00)00301-X, 2000.

Tett, S. F. B., Betts, R., Crowley, T. J., Gregory, J., Johns, T. C., Jones, A., Osborn, T. J., Öström, E., Roberts, D. L., and Woodage, M. J.: The impact of natural and anthropogenic forcings on climate and hydrology since 1550 , Clim. Dynam., 28, 3-34, https://doi.org/10.1007/s00382-006-0165-1, 2006.

Toniazzo, T., Collins, M., and Brown, J.: The variation of ENSO characteristics associated with atmospheric parameter perturbations in a coupled model, Clim. Dynam., 30, 643-656, https://doi.org/10.1007/s00382-007-0313-2, 2007.

Trenberth, K. E. and Fasullo, J. T.: An apparent hiatus in global warming?, Earth's Future, 1, 19-32, https://doi.org/10.1002/2013EF000165, 2013.

UNESCO: Tenth report of the joint panel on oceanographic tables and standards, Report, available at: http://unesdoc.unesco. org/images/0004/000461/046148eb.pdf (last access: 8 September 2017), 1981.

Valdes, P. J., Beerling, D. J., and Johnson, C. E.: The ice age methane budget, Geophys. Res. Lett., 32, L02704, https://doi.org/10.1029/2004GL021004, 2005.
Van der Wal, A.: Unified Model User Guide, chap. Radiation, p. 11, in: Matthews (1998), available at: http://www.ukscience.org/ _Media/UM_User_Guide.pdf (last access: 8 September 2017), 1998.

Visbeck, M., Marshall, J., Haine, T., and Spall, M.: On the specification of eddy transfer coefficients in coarse resolution ocean circulation models, J. Phys. Oceanogr., 27, 381-402, 1997.

Walters, D. N., Williams, K. D., Boutle, I. A., Bushell, A. C., Edwards, J. M., Field, P. R., Lock, A. P., Morcrette, C. J., Stratton, R. A., Wilkinson, J. M., Willett, M. R., Bellouin, N., BodasSalcedo, A., Brooks, M. E., Copsey, D., Earnshaw, P. D., Hardiman, S. C., Harris, C. M., Levine, R. C., MacLachlan, C., Manners, J. C., Martin, G. M., Milton, S. F., Palmer, M. D., Roberts, M. J., Rodríguez, J. M., Tennant, W. J., and Vidale, P. L.: The Met Office Unified Model Global Atmosphere 4.0 and JULES Global Land 4.0 configurations, Geosci. Model Dev., 7, 361-386, https://doi.org/10.5194/gmd-7-361-2014, 2014.

Warrilow, D.: Modelling of land surface processes and their influence on European climate, Met Office 20 (Dynamical Climatology Branch), Meteorological Office, Exeter, UK, 1986.

Warrilow, D. A. and Buckley, E.: The Impact of Land Surface Processes on the Moisture Budget of a Climate Model, Ann. Geophys., 7, 439-449, 1989.

Weaver, A. J., Sedlacek, J., Eby, M., Alexander, K., Crespin, E., Fichefet, T., Philippon-Berthier, G., Joos, F., Kawamiya, M., Matsumoto, K., Steinacher, M., Tachiiri, K., Tokos, K., Yoshimori, M., and Zickfeld, K.: Stability of the Atlantic meridional overturning circulation: A model intercomparison, Geophys. Res. Lett., 39, L20709, https://doi.org/10.1029/2012g1053763, 2012.

White, A. A. and Bromley, R. A.: Dynamically consistent, quasihydrostatic equations for global models with a complete representation of the Coriolis force, Q. J. Roy. Meteor. Soc., 121, 399418, https://doi.org/10.1002/qj.49712152208, 1995.

Williams, J. H. T., Smith, R. S., Valdes, P. J., Booth, B. B. B., and Osprey, A.: Optimising the FAMOUS climate model: inclusion of global carbon cycling, Geosci. Model Dev., 6, 141-160, https://doi.org/10.5194/gmd-6-141-2013, 2013.

Williams, J. H. T., Totterdell, I. J., Halloran, P. R., and Valdes, P. J.: Numerical simulations of oceanic oxygen cycling in the FAMOUS Earth-System model: FAMOUS-ES, version 1.0, Geosci. Model Dev., 7, 1419-1431, https://doi.org/10.5194/gmd-7-14192014, 2014.

Williams, K. D., Harris, C. M., Bodas-Salcedo, A., Camp, J., Comer, R. E., Copsey, D., Fereday, D., Graham, T., Hill, R., Hinton, T., Hyder, P., Ineson, S., Masato, G., Milton, S. F., Roberts, M. J., Rowell, D. P., Sanchez, C., Shelly, A., Sinha, B., Walters, D. N., West, A., Woollings, T., and Xavier, P. K.: The Met Office Global Coupled model 2.0 (GC2) configuration, Geosci. Model Dev., 8, 1509-1524, https://doi.org/10.5194/gmd-8-15092015, 2015.

Willmott, C. J., Rowe, C. M., and Mintz, Y.: Climatology of the terrestrial seasonal water cycle, J. Climatol., 5, 589-606, https://doi.org/10.1002/joc.3370050602, 1985.

Wilson, D.: Unified Model User Guide, chap. Precipitation, p. 32, in: Matthews (1998), available at: http://www.ukscience.org/ _Media/UM_User_Guide.pdf (last access: 8 September 2017), 1998. 
Wilson, M. F. and Henderson-Sellers, A.: A global archive of land cover and soils data for use in general circulation climate models, J. Climatol., 5, 119-143, https://doi.org/10.1002/joc.3370050202, 1985.
Zhang, L. P. and Wang, C. Z.: Multidecadal North Atlantic sea surface temperature and Atlantic meridional overturning circulation variability in CMIP5 historical simulations, J. Geophys. Res.Oceans, 118, 5772-5791, https://doi.org/10.1002/jgrc.20390, 2013. 